\title{
Genome-wide identification, evolution, expression, and alternative splicing profiles of peroxiredoxin genes in cotton
}

\author{
Yulong Feng Equal first author, 1 , Renhui Wei Equal first author, ${ }^{2}$, Aiying Liu ${ }^{2}$, Senmiao Fan ${ }^{2}$, JinCan Che ${ }^{1}$, Zhen Zhang ${ }^{2}$, Baoming \\ Tian $^{1}$, Youlu Yuan ${ }^{2}$, Gongyao Shi ${ }^{\text {Corresp., } 1}$, Haihong Shang ${ }^{\text {Corresp. 1, } 2}$ \\ ${ }^{1}$ Zhengzhou University, Zhengzhou Research Base, State Key Laboratory of Cotton Biology, Zhengzhou, China \\ ${ }^{2}$ Chinese Academy of Agricultural Sciences, State Key Laboratory of Cotton Biology, Key Laboratory of Biological and Genetic Breeding of Cotton, The \\ Ministry of Agriculture, Institute of Cotton Research, Anyang, China \\ Corresponding Authors: Gongyao Shi, Haihong Shang \\ Email address: shigy@zzu.edu.cn, shanghaihong@caas.cn
}

Peroxiredoxin (PRX) is a ubiquitous thioredoxin-dependent peroxidase that can eliminate excessive free radicals produced by stress and protect cells from oxidative damage. PRXs are also involved in reactive oxygen species (ROS)- and redox-dependent signaling by performing redox interactions with other proteins and modify their redox status. At present, PRX family identification, evolution and regulation research has been conducted in some plants; however, systematic research about this family is lacking in cotton. In this study, a total of 44 PRXs were identified in the cotton genome. Phylogenetic and conserved active site analyses showed that the PRXs were divided into six subfamilies according to the conserved site (PxxxTxxC...S...W/F) and conserved cysteinyl residues positions. Segmental duplication and polyploid events were the main methods for PRX family expansion, and the PRXs of diploid G. arboreum were the donors of PRXs in the D subgenomes of allotetraploid G. hirsutum and G. barbadense during the evolution of the PRX family. qRT-PCR analysis confirmed that cis-acting elements play important roles in regulating the expression of PRXs. Alternative splicing events occurred in GhPRX14-D that can increased the complexity of transcripts in G. hirsutum. Subcellular localization showed that most PRX members were located in chloroplasts, the cytoplasmic membrane and the nucleus. Our results provide systematic support for a better understanding of PRXs in cotton and a starting point for further studies of the specific functions of PRXs in cotton. 


\section{Genome-wide identification, evolution, expression, 2 and alternative splicing profiles of peroxiredoxin 3 genes in cotton}

4 Yulong Feng ${ }^{1 *}$, Renhui Wei ${ }^{2 *}$, Aiying $\mathrm{Liu}^{2}$, Senmiao Fan ${ }^{2}$, Jincan $\mathrm{Ch}^{2}$, Zhen Zhang ${ }^{2}$, Baoming

5 Tian $^{1}$, Youlu Yuan ${ }^{2}$, Gongyao Shi ${ }^{1}$, Haihong Shang ${ }^{1,2}$

$6{ }^{1}$ Zhengzhou University, Zhengzhou Research Base, State Key Laboratory of Cotton Biology,

7 Zhengzhou, China

$8{ }^{2}$ Chinese Academy of Agricultural Sciences, State Key Laboratory of Cotton Biology, Key

9 Laboratory of Biological and Genetic Breeding of Cotton, The Ministry of Agriculture, Institute

10 of Cotton Research, Anyang

12 Corresponding Author:

13 Gongyao Shi ${ }^{1}$

14 100Kexue Road, Zhengzhou, Henan P. R., China

15 Email address: shigy@zzu.edu.cn

16 Haihong Shang ${ }^{1,2}$

17100 Kexue Road, Zhengzhou, Henan P. R., China

18 Email address: shanghaihong@caas.cn

$19 *$ These authors contributed equally to this work. 


\section{Abstract}

Peroxiredoxin (PRX) is a ubiquitous thioredoxin-dependent peroxidase that can eliminate excessive free radicals produced by stress and protect cells from oxidative damage. $P R X s$ are also involved in reactive oxygen species (ROS)- and redox-dependent signaling by performing redox interactions with other proteins and modify their redox status. At present, $P R X$ family identification, evolution and regulation research has been conducted in some plants; however, systematic research about this family is lacking in cotton. In this study, a total of $44 P R X s$ were identified in the cotton genome. Phylogenetic and conserved active site analyses showed that the $P R X s$ were divided into six subfamilies according to the conserved site (PxxxTxxC...S...W/F) and conserved cysteinyl residues positions. Segmental duplication and polyploid events were the main methods for PRX family expansion, and the PRXs of diploid G. arboreum were the donors of $P R X s$ in the D subgenomes of allotetraploid G. hirsutum and G. barbadense during the evolution of the $P R X$ family. qRT-PCR analysis confirmed that cis-acting elements play important roles in regulating the expression of $P R X s$. Alternative splicing events occurred in GhPRX14-D that can increased the complexity of transcripts in G. hirsutum. Subcellular localization showed that most $P R X$ members were located in chloroplasts, the cytoplasmic membrane and the nucleus. Our results provide systematic support for a better understanding of $P R X S$ in cotton and a starting point for further studies of the specific functions of $P R X S$ in cotton.

\section{Introduction}

The peroxiredoxin $(P R X)$ protein (EC 1.11.1.15) is a member of the thioredoxin-scaffold enzyme family and presents cysteine-dependent peroxidase activity against hydrogen peroxide substrates. $P R X$ is ubiquitous among living organisms and has been found in animals, plants, protozoa, parasites, yeast, bacteria and archaea (Knoops et al. 2007). At present, research on this protein has mainly focused on mammalian disease resistance based on the loss of the protein, which leads to an imbalance in the cellular redox state (Oláhová et al. 2009). As an antioxidant enzyme, $P R X$ is widely known to eliminate stress-induced excess free radicals in the body and protect cells from oxidative damage (Hofmann et al. 2002). $P R X$ not only reduces the damage caused by oxidative stress but also enhances the activity of natural killer cells (Nonn et al. 2003), regulates cell proliferation, differentiation and apoptosis (Lee et al. 2003), and protects free radicalsensitive proteins (Wenders et al. 2003).

In plants, a total of $10 P R X$ family members were previously identified in the Arabidopsis (Arabidopsis thaliana) genome and four were found to be targeted to chloroplasts (Baier \& Dietz 1997; Horling et al. 2001), where they play important roles in chloroplast detoxification (Dietz et al. 2006). Some recent studies have demonstrated that 2-Cys $P R X$ participates in chloroplast enzyme oxidation in the dark in Arabidopsis (Pérez-Ruiz et al. 2017). The Fd-FTR-Trxs and NTRC redox systems of chloroplasts are integrated via the redox balance of 2-Cys PRX (PérezRuiz et al. 2017), and the chloroplast 2-Cys $P R X$ functions as a thioredoxin oxidase in the redox regulation of chloroplast metabolism (Pérez-Ruiz et al. 2017). Subsequently, Yoshida et al dissected the "dark side" of chloroplast redox regulation and provided insights into the thioredoxin-like2 (TrxL2)/2-Cys peroxiredoxin (2-CysPRX) redox cascade as a molecular basis for oxidative thiol modulation in chloroplasts. 2-CysPRX serves as an electron sink in the thiol 
71 network, which is important for the oxidation of reductively activated proteins and represents the missing link in the reversal of thioredoxin-dependent regulation (Vaseghi et al. 2018). All of these studies show that $P R X$ plays important roles in the chloroplast redox system. In addition to its peroxidase function, 2-CysPRX has been proposed to be involved in the water-water cycle (WWC) and hydrogen peroxide $\left(\mathrm{H}_{2} \mathrm{O}_{2}\right)$-mediated signaling in plastids (Awad et al. 2015). The WWC is of particular importance in protecting the photosynthetic apparatus from photooxidative damage. Many proteins that interact with 2-CysPRX have been identified, such as thioredoxinrelated electron donors (e.g., chloroplastic drought-induced stress protein of $32 \mathrm{kDa}$ and atypical cysteine histidine-rich thioredoxin 2) and enzymes involved in chlorophyll synthesis (e.g., protochlorophyllide oxidoreductase B) or carbon metabolism (e.g., fructose-1,6-bisphosphatase) (Cerveau et al. 2016). In addition, $P R X$ plays important roles in root growth (Finkemeier et al. 2005), photosynthesis protection (Lamkemeyer et al. 2006), antioxidant activity (Pulido et al. 2010) and drought tolerance (Fichman et al. 2018) in Arabidopsis. However, research on the $P R X$ gene in cotton is lacking, and only a few studies have shown that the $P R X$ gene is significantly upregulated in response to drought stress (Zhang et al. 2016). The availability of functional and structural information about $P R X$ has increased rapidly in the past decade. For example, all the proteins in the family have conserved Cys residues at the $\mathrm{N}$ terminus and some members also have conserved Cys residues at the $\mathrm{C}$ terminus. These conserved Cys residues can be used to divide the PRX proteins into two subfamilies, namely, 1-CysPRX and 2-CysPRX (Dietz 2011). However, the distinction between the functions of 2-Cys and 1-Cys is not particularly useful as a global classifier because representatives of each type seem to exist within all the subfamilies (Hall et al. 2011). Some studies have instead proposed classifying PRXs based on structural and sequence information at the reactive cysteine active site (Soito et al. 2011), and the functional site profiling method (also referred to as conserved active site profiling) (Nelson et al. 2011) and the Deacon Active Site Profiler (DASP) tool (Huff et al. 2005) have been used to analyze the sequence conservation near the catalytic cysteine structure through bioinformatics analysis. Here, we compare the mechanistic method (using active structural sites) to the traditional method (determining the positions and numbers of conserved cysteinyl residues) to provide a global classification and localization of the $P R X$ genes in cotton. In this study, we identified all of the $P R X$ genes in four cotton species (Gossypium hirsutum, Gossypium raimondii, Gossypium barbadense and Gossypium arboreum), evaluated their evolutionary relationships and performed physical mapping to the chromosomes of each cotton species. In addition, we systematically analyzed the gene structures, conserved active sites and cis-acting elements of all the identified $P R X$ genes in these four cotton species. To explore the functions of abiotic stress and hormoneinduced cis-acting elements in the $P R X$ gene promoters, we carried out experiments on the expression trends of the $P R X s$ under different stresses. The expression levels of $P R X s$ in cotton tissues and organs were analyzed using G. hirsutum TM-1 transcriptome data (Zhang et al. 2015), and the alternative splicing (AS) profiles of the $P R X S$ were identified and verified by RTPCR. Finally, to determine the localizations of the $P R X$ proteins in cells, we carried out subcellular localization experiments with Agrobacterium tumefaciens-infected tobacco. These results provide a solid foundation for the study of the distribution, structure and evolution of the cotton $P R X$ family, and the regulatory mechanisms, transcript abundances and cellular localizations of these $P R X s$ will provide important information for follow-up studies of their functional differentiation and applications.

\section{Materials and methods}




\section{Sequence sources}

117 G. raimondii (Gossypium raimondii L.,JGI) (Accession: PRJNA171262) (Paterson et al. 2012)

118 and G. hirsutum (Gossypium hirsutum L., NAU) (Accession: PRJNA248163) (Zhang et al. 2015)

119 genomic data files were obtained from the JGI database (https://genome.jgi.doe.gov/portal/); $G$.

120 arboreum (Gossypium arboreum L., CRI) (Accession: PRJNA382310) (Du et al. 2018) and G.

121 barbadense (Gossypium barbadense L., Hau) (Accession: PRJNA433615) (Wang et al. 2018)

122 genomic data files were downloaded from the CottonGen database (https://www.cottongen.org/).

123 The following protein sequence data were obtained from the corresponding databases.

124 Arabidopsis (Arabidopsis thaliana L.) (Accession: SRA009031) (Filichkin et al. 2010) protein

125 sequence data were obtained from The Arabidopsis Information Resource

126 (http://www.arabidopsis.org). Rice (Oryza sativa L.) (Ouyang et al. 2007) protein sequence data

127 were downloaded from the Rice Genome Annotation Project

128 (http://rice.plantbiology.msu.edu/index.shtml). Cacao (Theobroma cacao L.) (Accession:

129 PRJNA51633) (Motamayor et al. 2013) protein sequence data were obtained from the JGI

130 database (https://genome.jgi.doe.gov/portal/), and grapevine (Vitis vinifera L.) (GenBank:

131 CU459218-CU462737) (Jaillon et al. 2007) protein sequence data were obtained from the

132 Ensembl Plants database (http://plants.ensembl.org/index.html).

\section{Identification and conserved active site analysis of the $P R X$ family in cotton}

134 The PRX Pfam domain ids (PF08534.9, PF00578.20, PF10417.8) in cotton were identified using the $P R X$ protein sequence of $G$. hirsutum on the EMBL-EBI

136 (https://www.ebi.ac.uk/Tools/hmmer/) website. The Pfam model files were downloaded from the

137 Pfam database (http://pfam.xfam.org/) (Finn et al. 2009). The protein databases of four cotton

138 species (G. raimondii, G. arboreum, G. hirsutum, and G. barbadense) and Arabidopsis, Rice,

139 Cacao, and Grapevine were searched with hmmsearch (v3.2.1) (https://www.ebi.ac.uk/Tools/hm

$140 \underline{\mathrm{mer} / \mathrm{search} / \mathrm{hmmsearch}})(\mathrm{E}<=0.001)$. All possible $P R X$ genes were identified in these 8 crop

141 species. The BLAST program was used to compare the sequences to the Arabidopsis protein

142 database $\left(\mathrm{p}<=1 \mathrm{E}^{-10}\right)$, and then, the false positive $P R X$ genes were deleted on the basis of the

143 Arabidopsis protein annotation file (https://www.arabidopsis.org/). To further ensure the

144 accuracy of each candidate $P R X$, ClustalW in the MEGA7 (https://www.megasoftware.net/)

145 software was used to compare the candidate $P R X$ protein sequences with the conserved active

146 sites and positions of conserved cysteinyl residues in the $P R X$ proteins in the $P R X$ protein

147 database (http://csb.wfu.edu/prex/) (Dietz 2011; Nelson et al. 2011) and delete sequences with no

148 conserved active site (PxxxTxxC...S ..W/F). Blastp alignment of the identified $P R X$ proteins fro

$149 \mathrm{~m}$ the NCBI reference protein database was performed (percent identity $\geq 90 \%$ ). The theoretical

150 isoelectric point (pI) and molecular weight (MW) of the $P R X$ proteins were investigated with

151 ExPASy (http://web.expasy.org/protparam/) (Finn et al. 2014).

\section{Phylogenetic and gene structure analysis}

153 ClustalW in MEGA 7.0 software (Kumar et al. 2016) was used to compare the protein

154 sequences, and a phylogenetic analysis was then performed. A phylogenetic tree was constructed

155 in MEGA7 using the maximum likelihood (ML) method, the Poisson correction model, complete

156 deletion and bootstrap analysis performed with 1000 replicates. 
157 The exon/intron structures of the $P R X S$ were extracted from the corresponding cotton GFF files

158 by TBtools software (http://www.omicshare.com/forum/thread-1062-1-1.html), and the $P R X$

159 structure maps were drawn by GSDS 2.0 (http://gsds.cbi.pku.edu.cn/) (Hu et al. 2014). MEME

160 (4.11.4) (http://meme-suite.org/) (Bailey et al. 2006) was used to identify the conserved motifs of

161 the cotton PRXs with the following parameters: the maximum number of motifs was 10 and the

162 optimal width was $6 \leq 250$. Then, TBtools was used to construct a vector graph from the xml file

163 generated by MEME.

\section{Chromosomal mapping and gene duplication}

165 To reveal the chromosomal mapping and duplication relationships of $P R X s$ in cotton, genome 166 databases for G. raimondii, G. arboreum, G. hirsutum and G. barbadense were constructed. The 167 physical positions of $P R X s$ in cotton were fetched from the corresponding GFF files. $P R X$ family

168 duplication data were identified by the MCScanX program $\left(\mathrm{p}<=1 \mathrm{E}^{-20}\right)$ (Ding et al. 2015), and a 169 comparative genome analysis of the $P R X$ family genes in these four cotton species was carried 170 out $\left(\mathrm{p}<=1 \mathrm{E}^{-20}\right)$ (Wang et al. 2013). Visualization was carried out with the CIRCOS

171 (http://circos.ca/) tool (Krzywinski et al. 2009). The substitution rates of synonymous (Ks) and

172 nonsynonymous $(\mathrm{Ka})$ sites were calculated by the KaKs calculator program (Suyama et al.

173 2006). The divergence time was calculated by the formula $\mathrm{T}=\mathrm{Ks} / 2^{\lambda}\left(\lambda=1.5 \times 10^{-8}\right)$ (Zhang et al.

174 2006), where Ks was the synonymous substitution of each locus and $r$ was the divergence rate of

175 plant genes. For dicotyledonous plants, $\mathrm{r}$ is considered to be $1.5 \times 10^{-8}$ synonymous substitutions

176 per site per year (Koch et al. 2000).

\section{Analysis of cis-acting elements in the promoter region}

178 By using the genome data files (GFF3) of the four cotton species, the promoter sequences of the $179 P R X$ genes (2500 bp upstream of the initiation codon "ATG") were extracted from the cotton 180 genome sequences (Wang et al. 2012). PlantCARE

181 (http://bioinformatics.psb.ugent.be/webtools/plantcare/html/search_CARE.html) (Lescot et al.

182 2002) was used to predict the cis-acting elements of the promoter sequences, and the abiotic

183 stress response, plant growth and development, and then the hormone-induced cis-acting

184 elements were analyzed (Table S2).

185 Based on the cis-acting elements identified in the promoter sequence, we used GSDS 2.0

186 (http://gsds.cbi.pku.edu.cn/) (Hu et al. 2014) to display the physical sites of the cis-acting

187 elements in the G. hirsutum promoter sequence.

\section{Plant material treatments and expression analysis}

189 To analyze the expression patterns of the $P R X$ genes, $\mathrm{PEG}, \mathrm{NaCl}$ and salicylic acid (SA) were 190 used to simulate drought stress, osmotic stress and SA hormone induction, respectively. The

191 seeds of G. hirsutum sGK9708 were soaked in flasks overnight, germinated in fine sand at $28^{\circ} \mathrm{C}$

192 in the dark for 2 days, and transferred to a greenhouse for hydroponic growth. The hydroponic

193 greenhouse conditions were as follows: $28^{\circ} \mathrm{C}$ day $/ 25^{\circ} \mathrm{C}$ night, 14 -hour photoperiod and $70 \%$

194 relative humidity. Plants were grown in Hoagland nutrient solution (Xing et al. 2019). At the

195 three-leaf stage, the seedlings were subjected to stress treatments. The cotton seedlings were

196 equally divided into four groups and transferred to nutrient solutions of the hydroponic box

197 supplemented with $200 \mathrm{mM}$ sodium chloride $(\mathrm{NaCl}), 15 \%$ PEG-6000, $0.1 \mathrm{mM}$ SA and a blank 
198 control for the salt, drought, hormone induction and control treatments, respectively. A total of 19920 cotton seedlings received each treatment, and each treatment was repeated three times. At 0 , $2001,3,6$, and 12 hours of treatment, four seedlings were randomly selected from four treatment 201 groups at each time point, and the leaves (second true leaf) and rhizomes were removed from the 202 seedlings and immediately frozen in liquid nitrogen. The leaves were stored at $-80^{\circ} \mathrm{C}$ before 203 RNA extraction.

204 Total RNA was isolated using an EasyPure Plant RNA Kit (TransGen, Beijing, China), and RNA 205 reverse transcription was performed using a TransScript reverse transcription system (AT341).

$206 G h-P R X$-specific primers (Table S3) were used to find candidate-specific primers on the

207

208

209

210

211

212

213

214

215

216

217

218

219

220 qPrimerDB-qPCR Primer Database (https://www.ncbi.nlm.nih.gov/) website. To ensure the specificity of the $G h-P R X$ gene primers, the candidate-specific primers were subjected to BLAST homologous comparison in the Primer-BLAST database of NCBI (https://www.ncbi.nlm.nih.gov/) (National Center for Biotechnology Information) to ensure that the specific primers amplified only their respective target gene fragments (Table S3). The general fluorescent dye mixture used was SYBR Green I (TransStart), and the reactions were performed with a 7500 Rapid Real-time PCR system (Roche). Ubiquitin 7 (UBQ7) (GenBank: DQ116441) was used as the internal standard reference to measure the expression levels of the cDNA genes. The volume of each reaction was $10 \mu \mathrm{l}$, and the reaction conditions were as follows: $94^{\circ} \mathrm{C}$ for $5 \mathrm{~min}$ and 40 cycles of $94^{\circ} \mathrm{C}$ for $5 \mathrm{~s}, 55^{\circ} \mathrm{C}$ for $30 \mathrm{~s}$ and $72^{\circ} \mathrm{C}$ for $30 \mathrm{~s}$. During the extension step, the fluorescence signal was measured, and the acquisition time was set to 30 s. Each cDNA sample was repeated three times, and the results were analyzed by the $2^{-\Delta \mathrm{CT}}$ method (Khan-Malek \& Wang 2011).

\section{Analysis of tissue expression and AS profiles of $P R X s$}

221

222

223

224

225

226

227

228

229

230

231

232

233

234

235

236

237

238

239
We used published G. hirsutum (TM-1) (Zhang et al. 2015) transcriptome data, including data from the roots, stems, leaves, cotyledons, petals, stamens, ovules, seeds, and 5, 10, 15 and 20 DPA fibers. The expression levels of $G h-P R X$ genes in various tissues were calculated using $\log 2$ (FPKM) values (Zhang et al. 2015). The expression values were normalized by Genesis software and illustrated with a heatmap by HemI 1.0 - Heatmap illustrator software (Sturn et al. 2002).

Samples of G. hirsutum sGK9708 RNA without treatment at $-80^{\circ} \mathrm{C}$ were obtained. Total RNA was isolated using the EasyPure Plant RNA Kit (TransGen, Beijing, China), and RNA reverse transcription was performed using the TransScript reverse transcription system (AT321). The obtained first-strand cDNA was used for subsequent RT-PCR amplification. The primers for synthesizing full-length cDNA were designed using Primer Premier 5.0 software (Premier Biosoft International, Palo Alto, CA). After RT-PCR, the amplification products were detected by $1.2 \%$ agarose gel electrophoresis. After recovery and purification, the PCR products were ligated with the pEASY-Blunt cloning vector (TransGen, Beijing, China) (The pEASY ${ }^{\circledR}$-Blunt cloning kit was purchased from TransGen Biotech, catalog number: CB101-01) (https://www.transgenbiotech.com/) and transformed into E. coli (Escherichia coli)-competent DH5 $\alpha$ cells (TransGen, Beijing, China). Thirty individual colonies were selected for positive PCR identification. The positive colonies were sequenced (Sangon, Shanghai), and the fulllength sequences were obtained. These sequences were compared by Splign 
240 (https://www.ncbi.nlm.nih.gov/sutils/splign/splign.cgi) and GSDS 2.0

241 (http://gsds.cbi.pku.edu.cn/index.php), and the AS events were displayed on the gene structure.

\section{Subcellular localization of $\boldsymbol{P} \boldsymbol{X} \boldsymbol{X}$ proteins}

243 The TargetP 1.1 (http://www.cbs.dtu.dk/services/TargetP/) server website (Emanuelsson et al. 244 2007) was used to predict and analyze the localization of G. hirsutum PRX proteins in plant cells.

245 To verify the distribution of $P R X s$ in plant cells, five pairs of homologous genes from among 15

246 Gh-PRX genes were selected, and the full-length coding sequences (CDSs) of the $P R X$ genes

247 with no terminator codon and restriction site were amplified and subcloned into the

248 pCAMBIA2300-35S-eGFP (CAMBIA) transient expression vector (The pCAMBIA2300-35S-

249 eGFP vector was assembled by inserting the 35S-eGFP fragment into the pCAMBIA2300 vector

250 skeleton in our laboratory). The accuracy of the 10 recombinant vectors was ensured by primer-

251 based PCR and sequencing analysis. Then, we cultured Nicotiana benthamiana seedlings at

$25228^{\circ} \mathrm{C}$ day $/ 25^{\circ} \mathrm{C}$ night with a 14-hour photoperiod and $70 \%$ relative humidity for 1 month. When

253

254

255

256

257

258

259

260

261 the third or fourth leaf was dark green and sufficiently thick, Agrobacterium tumefaciens harboring the recombinant vector was injected into the tobacco leaves (Poulsen et al. 2016) to introduce the recombinant vector into tobacco leaf epidermal cells, and the plants were cultured in darkness at $25^{\circ} \mathrm{C}$ for 24 hours and then under light for 24 hours. A square slice of $1 \mathrm{~cm}^{2}$ was cut next to the injection area, placed on a slide with PBS buffer, and then gently covered with a cover glass. The position of the fluorescent protein in tobacco epidermal cells was observed by laser confocal microscopy (Olympus FV1200). The pCAMBIA2300-eGFP (CAMBIA) empty vector without the $G h-P R X$ gene was used as a control. The nuclei were stained with DAPI solution (Solarbio) as a control (Kapuscinski 1995).

\section{Results}

\section{3 \\ Genome-wide identification and conserved motif analysis of the $P R X$ family in cotton}

To identify the $P R X$ genes of cotton, we used the redoxin domain, 1-cys-PRX_C domain and AhpC-TSA domain as references. The protein databases of four cotton species were searched by Hmmsearch (Bhaduri et al. 2004). Based on the conserved active sites and the positions of conserved cysteinyl residues, $44 P R X$ genes were retrieved (Table 1), of which 15, 8, 8 and 13 $P R X s$ were identified from G. hirsutum, G. raimondii, G. arboreum and G. barbadense, respectively. The PRXs were then divided into six subfamilies, named 2-CysPRX, 1-CysPRX, PRQ, PRXIIB, PRXIIE and PRXIIF, according to their conserved active sites, the positions of their conserved cysteinyl residues and the relevant literature (Dietz 2011; Nelson et al. 2011) (Figure 1).

We performed multiple sequence alignment of the $44 P R X$ proteins using ClustalW in MEGA7 and identified in detail the specific and conserved active sites of the $P R X$ proteins (Adak \& Begley 2017). The results showed that the active sites of the $P R X$ protein sequences were consistent with those (Figure 1) by which the $P R X$ family was classified in the PREX database (http://csb.wfu.edu/prex/). All $P R X$ family proteins have conserved P, T, C, S and W/F amino acid sites, and the fifth conserved amino acid in the PRXQ subfamily protein sequence is $\mathrm{F}$ (Phe). In addition, we refer to the position and number of conserved cysteine residues in the 
280 classification of subfamilies (Dietz 2011). 2-CysPRX has 2 Cys residues: Cys ${ }_{P}$

281 (FFYPLDFTFVCPTEI) is generally located in the N-terminal part of the protein at

282 approximately amino acid (aa) position 118, and $\mathrm{Cys}_{\mathrm{R}}(\mathrm{EVCP})$ is located in the C-terminal part

283 of the protein at approximately aa position 240 (Figure 1). The two catalytic Cys residues in

284 PRXQ are separated by 4 amino acids (Figure 1) (Kong et al. 2000). The two catalytic residues

285

286

287

288

289

290

291

292

293

294

295

296

297

298

299 of PRXII, Cysp and $\mathrm{Cys}_{R}$, are separated by 24 amino acids. The subclassification of PRXII proteins has always been based on their subcellular localization (Dietz 2011), In addition, we compared the known PRXII proteins in Arabidopsis, rice and cotton and analyzed the differences between their conserved sequences, which facilitates a more accurate classification of PRXs (Figure S1). PRXIIE proteins are localized in the chloroplast (Mhamdi \& Van Breusegem 2018; Romero-Puertas et al. 2007) and share the conserved sequences

(FGLPGAYTGVCSQ....C.S...W). PRXIIF proteins are localized to the mitochondria (Horling et al. 2002), and display a conserved motif (Figure S1). Compared with the PRXIIF protein sequence in Arabidopsis, the $\mathrm{S}$ (serine) conserved was mutated to A (alanine) in cotton. The second cysteinyl (Cys) in the protein sequences of some genes originally predicted to belong to the PRXIIB subgroup (GbPRX6-A, GhPRX3-A, GhPRX11-D, GrPRX1 and GaPRX1) was mutated to $\mathrm{V}$ (Valine) (Figure 1) (Table S5), resulting in these genes having a cysteine residue only at N-terminal amino acid position 50 and being classified as 1-CysPRX. Typical 1-CysPRX proteins do not have a second Cys (Figure 1) (Dietz 2011) and only have Cysp followed by a peroxide domain.

300 The MW and $\mathrm{pI}$ of the $P R X S$ were calculated using the Compute $\mathrm{pI} / \mathrm{Mw}$ tool on the ExPASy 301 (https://web.expasy.org/compute pi/) website. The encoded protein lengths of the $44 P R X$ genes

302

303

304

305 varied from 100 to 300 amino acids, the predicted MWs were 13-30 kilodaltons (kDa), and the pI values were approximately 4.0-10.0. Subcellular localization analysis predicted that 17 of the 44 proteins localized to the chloroplasts (Table S4); thus, these members of the $P R X$ family may be involved in regulating the redox status of chloroplast proteins.

\section{Phylogenetic and gene structure analysis of $P R X s$ in cotton}

307 We constructed a phylogenetic tree using $74 P R X S$ from eight dicot species (G. raimondii, G. 308 arboreum, G. hirsutum, G. barbadense, Arabidopsis, rice, cacao, grapevine). The results show 309 that the cotton $P R X$ genes are divided into six subfamilies: 2-CysPRX, PRXQ, PRXIIE, PRXIIB, 310 PRXIIF and 1-CysPRX (Figure 2). Moreover, the cotton $P R X$ genes were clustered within every 311 clade, indicating that these genes had undergone specific expansions in all six subfamilies. A

312 conserved domain analysis helped to clarify the functional evolution and evolutionary

313 relationships of cotton $P R X s$. A total of 10 conserved motifs were identified in the $P R X$ proteins

314 of the 4 cotton species. The motif logo of these conserved motifs is shown in Figure S2, and the

315 flags for the 10 conserved motifs are shown in Figure 3C. The number of conserved motifs in 316 each $P R X$ protein ranged from 4 to 9 . There were four motif fragments containing conserved 317 active structural sites (motif 1 , motif 4, motif 5 and motif 6) (Figure 3C), and the details can be 318 seen in Figure S3. The conserved structural sites in the PRXIIB, PRXIIE, PRXIIF, 1-CysPRX 319 and PRXQ subfamilies are located in motif 1, while the conserved structural sites in 2-CysPRX and 1-CysPRX are composed of motif 4, motif 5 and motif 6 . Compared with the motifs containing conserved active sites, the seven other motifs $(2,3,7,8,9,10)$ play important roles in the functional differentiation of $P R X$ family genes. 
323 Exon-intron structural differences play a key role in the evolution of polygene families. We

324 found that the number of introns in the $44 P R X$ genes ranged from 0 to 6. PRXs in the same

325 subfamily showed a similar exon-intron structure (Figure 3B). The PRXIIB subfamily contained

326 five intron sequences of different lengths. PRXIIE has no introns, and PRXIIF has 4 introns.

327 PRXQ contained three introns, and most of the 2-CysPRX and 1-CysPRX subfamily genes also

328 contained the same number of introns. However, there was an intron sequence before the

329 translation initiation site (TIS) in GbPRX5-A and GbPRX14-D. Introns before the TIS are

330 integral parts of genes and play important roles in regulating gene expression (Li et al. 2013).

\section{Chromosome mapping and duplication analysis}

332 The $P R X$ genes were physically mapped to the chromosomes of G. hirsutum and G. barbadense.

333 We found that the mapping of $P R X s$ to the chromosomes of these two cotton species was similar

334 (Figure 4A and 4B), which shows that the genes of this family were conserved during evolution.

335 However, the homologs of three of these PRX genes (GbPRX6-A, GhPRX11-D and GbPRX8-D),

336 which are marked in black in the figure, may have been lost during evolution. There are six pairs

337 of homologous genes in the G. hirsutum PRX family, which are distributed on chromosomes

338 Gh_A01, Gh_A04, Gh_A08, Gh_A10, Gh_D01, Gh_D04, Gh_D08 and Gh_D10. Among the 15

$339 G h-P R X$ genes, GhPRX $3-A$ was localized to scaffolds, and its exact position has not yet been

340 determined. There are five pairs of $P R X$ homologous genes in $G$. barbadense, which were

341 mapped to chromosomes Gb_A01, Gb_A08, Gb_A10, Gb_D01, Gb_D08 and Gb_D10.

342 Compared with those of G. hirsutum, the PRXS on Gb_A04 of G. barbadense were lost;

343 therefore, one pair of homologous genes was missing. The comparative genomic analysis of

$344 P R X s$ between $G$. hirsutum and $G$. barbadense showed that GbPRX6-A on Gb_A05 originated

345 from a translocation of GhPRX11-D on Gh_D05 (Figure 4B and Figure S4). Based on the

346 physical chromosome mapping analysis and comparison of $P R X s$ between the G. arboreum and

347 G. raimondii genomes, we found that only the location of GaPRX5 and GrPRX6 on Chr02 was

348 relatively conserved in these two cotton species (Figure 4C-4D and Figure S4).

349 We identified 8 pairs of duplicates among the $15 P R X s$ of G. hirsutum (GhPRX8-D:GhPRX1-A,

350 GhPRX9-D:GhPRX2-A, GhPRX10-D:GhPRX12-D, GhPRX10-D:GhPRX4-A, GhPRX12-

351 D:GhPRX4-A, GhPRX5-A:GhPRX13-D, GhPRX15-D:GhPRX7-A, and GhPRX14-D:GhPRX6-A)

352 (Figure 4A), and these duplicates are located on six pairs of chromosomes (Gh_A01:Gh_D01,

353 Gh_A04:Gh_D04, Gh_D05:Gh_D08, Gh_A08:Gh_D05, Gh_A08:Gh_D08, and

354 Gh_A10:Gh_D10). With the exception of GhPRX10-D:GhPRX12-A and GhPRX10-D:GhPRX4-

$355 A$, which underwent segmental duplication, these duplicates were produced during the process of

356 genomic polyploidization. Compared with those in $G$. hirsutum, the duplicated genes on the $G$.

357 barbadense Gb_A04 and Gb_D04 chromosomes were altered (Figure 4B). GbPRX8-D on the

358 Gb_D04 chromosome was conserved, although the corresponding homologous gene on Gb_A04

359 was lost during evolution. The other duplicated genes were the same as those in G. hirsutum and

360 remained conserved. The $P R X s$ of the diploid G. arboreum genome are very similar to the $P R X s$

361 of the tetraploid $G$. hirsutum and G. barbadense D subgenome, only GaPRX5 was lost during

362 evolution, and segmental duplication genes on Chr05 and Chr08 chromosomes were highly

363 homologous (Figure 4D and Figure S4). However, in G. raimondii, these segmentally duplicated

364 genes were physically located on the Gr_chr04 and Gr_chr09 chromosomes (Figure 4C).

365 According to a KaKs calculation of the duplicated gene pairs in G. raimondii and G. arboreum

366 (Table S1), the divergence time of the duplicated genes (GrPRX3:GrPRX7) on the G. raimondii

Peer] reviewing PDF | (2019:12:44008:5:0:NEW 6 Dec 2020) 
367 chromosomes Gr_chr04 and Gr_chr09 was 24.81 MYA, while the divergence time of the

368 duplicated genes (GaPRX3:GaPRX7) on G. arboreum Ga_chr05 and Ga_chr08 was 23.98 MYA.

369 The divergence time of these genes on Chr05 and Chr08 in G. hirsutum and G. barbadense was

370

371 23.2MYA. A comparative analysis of four cotton $P R X s$ also showed that these segmental duplication genes were highly homologous, and the physical location of the PRXs in G. arboreum

372 highly overlapped with that on the D subgenomes of G. hirsutum and G. barbadense.

374

375

376

377

378

379

380

381

382

383

384

385

386

387

388

389

390

391

392

393

394

395

396

397

398

399

400

401

402

403

404

405

406

407

\section{Analysis of cis-acting elements in promoter regions}

In plants, cis-acting elements play an important role in gene expression regulation. We found many cis-acting elements in the promoters of the PRX genes in the four cotton species (Table S2) and identified three main types of cis-acting elements.

The first type of cis-acting element was responsive to abiotic stress (Figure 5A). There were nine types of elements (ARE, DRE1, LTR, MBS, MYC, STRE, TC-rich repeats, WRE3, and WUNmotif) in this category, among which the most abundant cis-acting elements were related to drought stress. The elements related to drought stress were MBS and MYC, and MYC was more frequent. GhPRX5-A, GhPRX6-A, GhPRX7-A, GhPRX9-D, GhPRX13-D, GbPRX1-A, GbPRX2$A$, GbPRX5-A, GbPRX8-D, GbPRX9-D, GrPRX2, GrPRX8 and GrPRX5 contained more than five drought-related elements among the four cotton species. Second in terms of presence, the cis-acting elements involved in the response to osmotic stress and defense were STRE- and TCrich. In addition, there were elements that responded to anaerobic conditions, hypothermia and wounding.

The second type of $c i s$-acting element was responsive to plant hormones (Figure 5B). There were ten types of elements (ABRE, AuxRR-core, CGTCA-motif, ERE, GaRE-motif, P-box, TATCbox, TCA-element, TGaCG-motif, and TGa-element) that responded to abscisic acid, auxin, ethylene, gibberellin and SA. Among them, ABRE (ABA) and ERE were the most abundant in the cotton $P R X$ gene promoters and were found in 31 and $36 P R X$ genes, respectively. We also found three types of elements (GaRE-motif, P-box and TATC-box) involved in the gibberellin response in the $P R X$ promoters. Among them, there were 2 GaRE-motifs, 3 TATC-boxs and 14 P-boxs in 44 promoters. In addition, auxin response elements (AuxRR-core and TGA-element), methyl jasmonate response elements (MeJA and TGACG-motif), and SA response elements (TCA-element) were found in many $P R X$ promoters.

The third type of cis-acting element was related to plant growth and development (Figure 5C). There were nine such types of elements (AACA-motif, AT-rich element, CAT-box, circadian, GCN4-motif, HD-Zip 1, MBSI, MYB, and O2-site). Among them, only one circadian element was involved in circadian regulation, and this element was found in the promoters of only two $P R X$ genes (GhPRX10-D and GhPRX11-D) in G. hirsutum. PRXs may be less sensitive to circadian rhythms. The largest number of cis-acting elements were MYB protein binding sequence sites, and two types of MYB protein sequence binding site elements (MBSI and MYB) were identified. In addition, some cis-acting elements (GCN4-motif and AACA-motif) involved in endosperm expression, cis-acting regulatory elements (CAT-box) involved in meristem expression, and response elements involved in palisade mesophyll cell differentiation (HD-Zip 1) were also found, and some light-related cis-acting elements were also identified (Figure S5). 


\section{Expression profiles of $P R X s$ in $G$. hirsutum under stress}

409

410

411

412

413

414

415

416

417

418

419

420

421

422

423

424

425

426

427

428

429

430

431

432

433

434

435

436

437

438

439

440

441

442

443

444

445

446

447

448

449

450

To investigate the regulation of $P R X$ expression by cis-acting promoter elements, we analyzed the cis-acting elements that respond to drought (MBS and MYC), osmotic stress (STRE and TCrich) and SA (TCA-element) in the promoter regions of Gh-PRX genes. The physical positions of these five $c i s$-acting elements in the promoter regions of the $G h-P R X$ genes were plotted (Figure 6). An element (MYC) involved in drought induction was present in all the Gh-PRX promoter regions, and the effects of drought on the expression levels of these genes were predicted to be strong.

We used PEG-6000, NaCl and SA to treat hydroponic G. hirsutum seedlings. Gene samples were extracted from G. hirsutum for qRT-PCR verification (Figures 7 and 8 ). The expression level of genes in each time period was normalized to that at the 0 hour time point. The results showed that nine $P R X s$ were upregulated in plant roots under salt stress, including GhPRX1-A, GhPRX2A, GhPRX5-A, GhPRX10-D, GhPRX11-D, GhPRX12-D, GhPRX13-D, GhPRX14-D and GhPRX15-D (Figures 7A, B, E, J, K, L, M, N, O). The promoter regions of GhPRX11-D, GhPRX14-D and GhPRX15-D were rich in TC-rich elements, while GhPRX5-A, GhPRX10-D, GhPRX12-D and GhPRX13-D were rich in STRE elements. Some genes were repressed under stress for 1 hour, such as GhPRX4-A, GhPRX6-A, GhPRX8-A and GhPRX9-D (Figures 7D, F, H, I), in which GhPRX4-A, GhPRX6-A and GhPRX9-D were rich in STRE elements. However, in salt-treated leaves, the expression of most genes was inhibited, including GhPRX2-A, GhPRX4A, GhPRX5-A, GhPRX6-A, GhPRX8-D, GhPRX9-D, GhPRX10-D, GhPRX12-D and GhPRX13$D$ (Figures 8B, D, E, F, H, I, J, L, M), including the seven genes rich in STRE elements. Five genes were slightly upregulated under salt treatment, including GhPRX1-A, GhPRX3-A, GhPRX11-D, GhPRX14-D and GhPRX15-D (Figures 8A, C, K, N, O). Among them, GhPRX11$D, G h P R X 14-D$ and GhPRX15-D are rich in TC-rich elements. Although GhPRX14-D was slightly lower than the control at 0 hours, it was higher than the expression of the control under stress. Under SA stress, five PRXs were downregulated in roots (GhPRX1-A, GhPRX2-A, GhPRX4-A, GhPRX6-A and GhPRX8-D) (Figures 7A, B, D, F, H), seven PRXs were downregulated in leaves (GhPRX2-A, GhPRX4-A, GhPRX5-A, GhPRX6-A, GhPRX8-D, GhPRX10-D and GhPRX12-D) (Figures 8B, D, E, F, H, J, L), and no significant upward trend was observed in all PRXs. Only GhPRX8-D in the root and GhPRX13-D in the leaf first decreased and then increased. GhPRX2-A, GhPRX4-A, GhPRX6-A and GhPRX8-D were rich in TCA-element cis-acting elements, and four genes were suppressed and downregulated in the roots and leaves.

MYC/MBS cis-acting elements exist in all Gh-PRX genes. Under drought stress simulated by PEG-6000, the expression of most Gh-PRX genes in roots first increased and then decreased (Figure 7). Especially at 1 hour, the expression levels of 10 of the $15 P R X$ genes increased significantly and then decreased rapidly (GhPRX1-A, GhPRX2-A, GhPRX4-A, GhPRX5-A, GhPRX6-A, GhPRX8-A, GhPRX10-D, GhPRX11-D, GhPRX13-D and GhPRX15-D) (Figure 7A, $\mathrm{B}, \mathrm{D}, \mathrm{E}, \mathrm{F}, \mathrm{H}, \mathrm{J}, \mathrm{K}, \mathrm{M}$ and $\mathrm{O}$ ), which indicated that the $P R X S$ in roots were highly sensitive to drought stress and induced. However, in leaves, most $P R X s$ showed a downregulation trend, such as GhPRX2-A, GhPRX4-A, GhPRX5-A, GhPRX6-A, GhPRX8-D, GhPRX10-D and GhPRX12-D. Only GhPRX9-D showed the same expression as roots, first upregulated and then downregulated (Figure 8I). 


\section{Expression and AS profiles of PRXs in different tissues of $\boldsymbol{G}$. hirsutum}

452 It is important to analyze the expression of genes in plant tissues and organs to understand gene function. We analyzed the available transcriptome data of various tissues and organs of $G$. hirsutum TM-1 (Zhang et al. 2015), including the roots, stems, leaves, cotyledons, petals, stamens, ovules, seeds, and fibers at 5, 10, 15 and 20 DPA. A heatmap was used to show the expression of the PRX genes (Figure 9A). GhPRX3-A, GhPRX5-A, GhPRX10-D, GhPRX11-D and $G h P R X 13-D$ were expressed at low levels or not expressed in all tissues. GhPRX3 and GhPRX12 were highly expressed in all tissues, and the FPKM value of GhPRX14 expression level in roots and leaves was approximately 50-60.

460

Understanding and verifying the AS events of the G. hirsutum PRX family is an important step in

461 the study of gene functional differentiation. Five main types of AS events were used for further

462 analysis: exon skipping (ES), intron retention (IR), 5' or 3' alternative splice sites (A5SS or A3SS), alternative first exon (AFE), and alternative last exon (ALE). Because change in the CDS can modify protein sequence and function, only AS events located in the CDSs of the genes were used for further analysis. Using the full-length primers designed for the amplification of $P R X$ gene cDNA, RT-PCR amplification was performed using the leaf and root cDNA of G. hirsutum sGK9708 as a template. The results showed that the products obtained for GhPRX14-D included multiple fragments (Figures 9B, C and 9E); moreover, s everal bands with different levels of brightness and unequal size were present. Thus, we speculate that GhPRX14-D may have multiple transcripts. The PCR products of GhPRX14-D were recovered, purified and ligated into a cloning vector for replication and sequencing. Analysis of the obtained sequences showed two different transcripts of GhPRX14-D in the leaves of G. hirsutum (Table 2) and three in the roots. GhPRX14-D uses three AS methods, IR, ES and A3SS. GhPRX14-Leaf-AS2 and GhPRX14Root-AS2 use one nonstandard AS site: 5'-AG. AA-3' (3 clones and 2 clones), which retains 15 bases at the $3^{\prime}$ end of the first intron (Figure 9D). GhPRX14-Root-AS3 uses two nonstandard AS sites: 5'-AG. AT-3' (2 clones) and 5'-GG. TT-3' (2 clones), which retain 14 bases at the 3' end of the fourth intron. The second, third, and fourth exons were skipped (Figure 9D).

\section{Subcellular localization of $\boldsymbol{P R} \boldsymbol{X}$ proteins}

479 Determining the distribution of proteins in cells is an important step to verify protein function. Using the TargetP 1.1 Server (http://www.cbs.dtu.dk/services/TargetP/) website to predict and analyze proteins, we found that the $P R X$ proteins were mainly located in chloroplasts and plasma membranes. However, the specificity of a few gene prediction results was too low to determine protein localization (Table S4).

To verify the predicted subcellular localizations of the $P R X$ proteins, we selected $10 P R X s$ with high expression levels for subcellular localization analysis (5 pairs of homologous genes). We 486 constructed a transient expression 35s-PRX-eGFP vector for each gene that was used to verify the experimental purpose. The results showed that the eGFP fluorescence signal in the control group was dispersed throughout the tobacco leaf cells, while the fluorescence signals of GhPRX4- $A$ and GhPRX12-D, which are members of PRXIIB, were located in the cell membrane (Figure 10D-I), thus providing support for the accurate classification of PRXIIB subfamily members. The protein fluorescence signals of GhPRX7-A and GhPRX15-D, members of 1CysPRX, were located on the cell membrane and nucleus (Figure 10J-M and 10N-Q). GhPRX1- 
493

494

495

496

497

498

499

500

501

502

503

504

505

506

507

508

509

510

511

512

513

514

515

516

517

518

519

520

521

522

523

524

525

526

527

528

529

530

531

532

533

534

535

536

$A$ and GhPRX8-D of PRXIIE, GhPRX6- $A$ and GhPRX14-D of PRXIIF, GhPRX2-A and $G h P R X 9-D$ of 2-CysPRX, and their protein fluorescence signals were located in chloroplasts (Figure 10R-OO).

\section{Discussion}

$P R X$ is a ubiquitous and abundant protein and is very important for oxidation resistance and cell signal transduction. Recently, in plants, 2-CysPRX in chloroplasts was shown to regulate protein redox status and oscillate diurnally between hyperoxidation and reduction, thus protecting plants from a myriad of harsh environmental stresses (Lee et al. 2017) and further protecting prochlorophyllide synthesis, which takes place through the stimulation of an aerobic cyclase by the NTRC/2-CysPRX system (Stenbaek et al. 2008). 2-CysPRX deficiency inhibits photosynthesis and chlorophyll accumulation during plant development (Baier \& Dietz 1999). 2CysPRX proteins in plants are involved in key signaling processes, such as WWC and H2O2mediated signaling in plastids (Awad et al. 2015) and carbon metabolism (Cerveau et al. 2016), and they are presumed to act as plastidial thiol oxidases (Cerveau et al. 2019). These recent advances in understanding 2-CysPRX functions indicate that this family of genes is involved in the photosynthesis and antioxidation pathways in chloroplasts, and our subcellular localization in this study confirms that 2-CysPRX genes are mainly distributed in cotton chloroplasts (Figure 10R-OO). PRXQ represents approximately $0.3 \%$ of chloroplast proteins, and is localized on the thylakoid membrane. Data show that PRXQ is directly involved in photosynthesis (Lamkemeyer et al. 2006). $P R X$ type II exists in the cytoplasm, plastid and mitochondria as general antioxidant active proteins. In addition, type II $P R X$ proteins protect DNA from damage in vivo or in vitro (Banmeyer et al. 2005). 1-CysPRX proteins are targeted to the nucleus and cytosol in higher plants and related to seed dormancy and germination (Goldmark et al. 1992; Haslekås et al. 2003). However, a genome-wide identification or evolutionary analysis of the $P R X$ gene family has not been reported in cotton, although four cotton species have been sequenced. Here, we identified 15, 9, 8 and $13 P R X S$ from $G$. hirsutum, G. raimondii, G. arboreum and $G$. barbadense, respectively. All cotton $P R X$ protein sequences were aligned with the NCBI reference protein (refseq protein) database. We found that the study of this family of proteins in cotton was still in the prediction stage (Table S5) and that some predicted subclassifications were not entirely accurate. In terms of protein similarity, the sequences of the cotton $P R X$ family proteins were most similar to those of Durio zibethinus and Citrus sinensis.

We used the DASP method to classify the cotton $P R X$ proteins into subfamilies. The correct subfamily classification of the $P R X$ family has remained difficult because $P R X$ subfamily identity is usually independent of phylogenetic distribution; thus, the subfamilies do not correspond to the phylogenetic classification based on the PSI-BLAST method (Dietz 2011; Soito et al. 2011). Using the DASP method to classify proteins according to their conserved active functional sites can provide a more accurate subfamily classification (Nelson et al. 2011). We found that all cotton $P R X$ proteins contained a completely conserved active site cysteine (PXXXTXXCp), called peroxidatic cysteine $\left(\mathrm{CyS}_{\mathrm{P}}-\mathrm{SH}\right)$, which is the catalytic center of the peroxidase. The thiolate of $\mathrm{CyS}_{\mathrm{P}} \mathrm{SH}$ attacks the peroxide substrate (Dietz 2011), reducing the peroxide to alcohol and water or nitrite (Hofmann et al. 2002; König et al. 2002). PRX subfamily classification is based on conserved active site sequence information (PxxxTxxC...S...W/F) and gene structural similarity. To clarify the classification, we also referred to the traditional subclassification based on the positions of the conserved cysteinyl residues. The results showed 
537 that $39 P R X$ proteins were correctly classified in cotton using the DASP method, and the 538 sequences of the 5 incorrectly classified genes (GhPRX3-A, GhPRX11-D, GbPRX6-A, GrPRX1 539 and $G a P R X 1)$ were highly similar to the sequences of PRXIIB subfamily proteins with the second cysteine residue replaced (Figure 1). Thus, these proteins should be classified as 1CysPRX, although the currently available predictions for these five genes ( $G h P R X 3-A$, GhPRX11-D, GbPRX6-A, GrPRX1 and GaPRX1) still list them as PRXIIB (accession numbers: XP_016702396.1, XP_016684751.1,XP_016724513.1, XP_012440686.1, XP_017605848.1). Tandem gene duplication, segmental duplication and polyploid events are the main means of gene family expansion (Cannon et al. 2004). Thus, gene duplication events must be analyzed at the genome level. Our comparative genome analysis also showed that a large number of $P R X s$ are produced by segmental duplication and polyploid events, which greatly enriches the members of the PRX family. At present, G. raimondii (D5 genome) is generally considered to be the D subgenome donor of $G$. hirsutum (Li et al. 2015). However, a comparative analysis of the physical location and sequence of $P R X$ family genes in four cotton species showed that the gene information of PRXS in G. arboreum is more homologous to that in $G$. hirsutum and $G$. barbadense, which was verified by both the location information on the chromosome and the time of homologous genes divergence. Therefore, we speculate that the PRXs of diploid $G$. arboreum are the donors of PRXs in the D subgenomes of allotetraploid G. hirsutum and $G$. barbadense.

To understand the expression patterns of $P R X S$ during cotton growth and development, the effect of stress on gene expression must be investigated. We found abundant cis-acting elements related to abiotic stress, hormone induction and plant growth and development regulation in the promoter regions of these genes in cotton (Figure 5), suggesting that $P R X$ genes are widely involved in the growth and development of cotton plants. The qRT-PCR analysis showed that most $P R X s$ could be induced or repressed by abiotic stress and hormone treatments, indicating that $P R X s$ may play important roles in coping with stress. Many studies have shown that the expression level of PRXS respond to drought (Cho et al. 2012; Haddad \& Japelaghi 2015; Xu et al. 2015; Xu et al. 2019), abscisic acid (Baier et al. 2004; Haslekås et al. 2003), and ethylene stress (Tovar-Méndez et al. 2011); moreover, Arabidopsis overexpressing $P R X$ shows increased salt and low temperature tolerance (Jing et al. 2006). Based on these stresse-induced changes in $P R X$ expression, we aimed to understand the role of cis-acting elements in this regulation. Our study showed that expression of three genes (GhPRX11-D, GhPRX14-D and GhPRX15-D) rich in TC+rich elements was induced and three of the seven genes with STRE elements (GhPRX4-A, GhPRX6-A and GhPRX9-D) were repressed in roots and leaves under salt stress (Figure. 7 and 8). In some existing studies, $P R X$ RNA and protein levels in mung beans decreased under high salinity (Cho et al. 2012) while $P R X$ protein expression in rice (Oryza sativa L.) was upregulated under high salinity (Xu et al. 2015). These findings indicate that $P R X S$ are differentially expressed under salt stress, and TC-rich and STRE elements may play certain roles in the regulation of $P R X$ expression. Under treatment with SA hormone, the expression of most $P R X S$ is repressed. Studies have shown that SA can greatly alleviate oxidative damage under stress by activate the mechanism of scavenging reactive oxygen species and reducing the activity of antioxidant enzymes (Soltani Delroba et al. 2011), which may also lead to the inhibition of $P R X$ expression. We found that the expression of all PRXs rich in TCA-elements in cotton was repressed (Figure 7B, D, F, H and Figure 8B, D, F, H). To date, studies of TCA-elements in

581 plants have shown that these elements can be activated by SA (Salazar et al. 2007). Therefore, 582 we speculate that TCA-elements play an inhibitory role in PRX expression in cotton, which 
583 provides a reference for the regulation of genes by this element in other plants. Under drought 584 stress, the expression of 10 of $15 P R X s$ in G. hirsutum roots increased rapidly at 1 hour and then 585 decreased gradually (Figure 7A, B, D, E, F, H, J, K, M and O). In leaves, only GhPRX9-D was 586 upregulated and then downregulated, while the other $P R X S$ did not fluctuate or decreased slowly 587 within 12 hours (Figure 8). Previous studies in drought-stressed alfalfa showed that PRXs were 588 repressed in the shoot but induced in the root (Kang \& Udvardi 2012), roots are highly sensitive 589 to drought, which increases the production of intracellular reactive oxygen species (ROS) (Hu et al. 2011). Therefore, roots directly exposed to drought stress will rapidly upregulate the expression of $P R X S$ to regulate the level of ROS (Zhou et al. 2014). A decrease in the water potential in leaves may not be sufficient to induce the expression of $P R X s$ and downregulate the expression of $P R X S$ in leaves (Bhardwaj et al. 2014). Since MYC and MBS elements are present in all $P R X$ promoters, the role of MYC and MBS elements in regulating $P R X$ expression in different $G$. hirsutum tissues has not been determined. Since these cis-acting elements respond to stress, the verification of regulated gene expression depends on additional research data to identify the transcription factors that interact with these elements.

AS is a key posttranscriptional regulatory mechanism that can produce multiple transcripts and

600

601

602

603

604

605

606

607

608 protein isomers, enrich protein diversity and increase protein functional complexity. Studies have shown that AS is an important form of plant gene expression regulation (Syed et al. 2012) that is involved in many physiological metabolic processes, signal transduction and responses to external biotic and abiotic stresses in plants (Barbazuk et al. 2008; Mastrangelo et al. 2012). A large amount of data has shown that IR is the most common AS event (Campbell et al. 2006; Rauch et al. 2013; Reddy et al. 2013; Zhiguo et al. 2013) and ES is a less common event (Barbazuk et al. 2008). Our analysis of the AS events of PRXs in G. hirsutum showed that the main AS modes were IR, ES, and A5SS or A3SS (Table 2). By examining the type and location of AS, we found that $G h P R X 14-D$ has the same type of transcript in plant roots and leaves, GhPRX14-Leaf-AS2 and GhPRX14-Root-AS2 (Figure 9D and E). In addition, the specific transcript GhPRX14-Root-AS3 has two AS types, ES and A3SS. The existence of two or more AS types for each transcript as well as differential splicing of homologous genes are very common in plants (Chen et al. 2018; Zhang et al. 2019). We found that there were no AS events in GhPRX6-A, the homologous gene of GhPRX14-D, which indicated that the homologous gene was differentially expressed with respect to AS events. AS transcripts use two or more AS methods, and the differential splicing of homologous genes significantly increases transcript complexity and enriches protein types. Therefore, verifying the AS of PRXs can help us understand the distribution of the transcripts of this gene family in cotton and provide a valuable reference for future studies of the diversity of this protein family in cotton.

618 Determining the distribution of proteins in cells is an important step for analyzing the 619 subclassification and protein function of the PRX family. In this study, $10 P R X s$ with the highest expression level were selected, and $4 P R X$ proteins were found to be located in chloroplasts (Figure 10Z-GG and 10R-Y), and they belonged to the 2-CysPRX and PRXIIE subfamilies. In many other species, the two subfamily proteins have also been proven to be mainly located in chloroplasts (Baier \& Dietz 1997). They mainly function in chloroplasts, including participating in the balance of the thiol redox system of chloroplasts (Pérez-Ruiz et al. 2017), metabolism regulation (Yoshida et al. 2018), and signal transduction (Awad et al. 2015). In the transient expression assay in onion epidermal cells, a green fluorescent protein-AtPER1 (1-CysPRX) fusion protein was also localized to the cytoplasm and nucleus. The localization information of 
628 cotton 1-CysPRX proteins also demonstrated that it was mainly located in the nucleus and 629 cytoplasmic membrane (Figure 10J-Q). Strangely, previous studies showed that PRXIIF is 630 mainly located in mitochondria (Horling et al. 2002; Iglesias Baena 2010) and decomposes 631 peroxides in the presence of glutaredoxins as a reductant. However, our localization of PRXIIF 632 proteins shows that it is also located in chloroplasts. Conservative sequence alignment of PRXII 633 proteins shows that the conserved $\mathrm{S}$ (serine) is mutated into A (alanine), which may be 634 characteristic of the PRXIIF sequence in chloroplasts. These results provide new research data 635 for PRXII subfamily classification and localization.

\section{Conclusions}

637 In this study, to thoroughly characterize the $P R X$ family and correct the current misclassification 638 of $P R X s$ in 4 cotton species, we identified 15, 8, 8 and 13 PRX genes from Gossypium hirsutum, 639 G. raimondii, G. arboreum and G. barbadense, respectively. Forty-four $P R X s$ were identified 640 and divided into six subfamilies, namely, 2-CysPRX, 1-CysPRX, PRQ, PRXIIB, PRXIIE and 641 PRXIIF. The distribution, evolution, regulation mechanism, alternative splicing and location of 642 these $P R X s$ in cotton were analyzed and identified in detail. This study provides the first 643 systematic report on $P R X S$ in cotton. It aims to provide a foundation for further research on 644 biological resistance to stress, anti-aging and disease resistance.

\section{Acknowledgments}

646 We would like to thank Peng Huo (The Institute of Cotton Research, Chinese Academy of 647 Agricultural Sciences) for assistance with laser confocal microscopy (FV1200, OLYMPUS).

\section{Abbreviations list}

649 PRX, Peroxiredoxin; SA, salicylic acid; IR, intron retention; ES, exon skipping; A5SS or A3SS, $6505^{\prime}$ or 3' alternative splice sites; AS, alternative splicing; pI, isoelectric point; MW, molecular 651 weight; and FPKM, Fragments Per Kilobase of exon model per Million mapped fragments.

\section{References}

653

654

655

656

657

658

659

660

661

662

663
Adak S, and Begley TP. 2017. RutA-catalyzed oxidative cleavage of the uracil amide involves formation of a flavin-N5-oxide. Biochemistry 56:3708-3709.

Awad J, Stotz HU, Fekete A, Krischke M, Engert C, Havaux M, Berger S, and Mueller MJ. 2015. 2-cysteine peroxiredoxins and thylakoid ascorbate peroxidase create a water-water cycle that is essential to protect the photosynthetic apparatus under high light stress conditions. Plant Physiology 167:1592-1603.

Baier M, and Dietz K-J. 1999. Protective function of chloroplast 2-cysteine peroxiredoxin in photosynthesis. Evidence from transgenic Arabidopsis. Plant Physiology 119:1407-1414.

Baier M, and Dietz KJ. 1997. The plant 2 - Cys peroxiredoxin BAS1 is a nuclear - encoded chloroplast protein: its expressional regulation, phylogenetic origin, and implications for its specific physiological function in plants. The plant journal 12:179-190. 
664

665

666

667

668

669

670

671

672

673

674

675

676

677

678

679

680

681

682

683

684

685

686

687

688

689

690

691

692

693

694

695

696

697

698

699

700

701

702

Baier M, Ströher E, and Dietz K-J. 2004. The acceptor availability at photosystem I and ABA control nuclear expression of 2-Cys peroxiredoxin-A in Arabidopsis thaliana. Plant and Cell Physiology 45:997-1006.

Bailey TL, Williams N, Misleh C, and Li WW. 2006. MEME: discovering and analyzing DNA and protein sequence motifs. Nucleic acids research 34:W369-W373.

Banmeyer I, Marchand C, Clippe A, and Knoops B. 2005. Human mitochondrial peroxiredoxin 5 protects from mitochondrial DNA damages induced by hydrogen peroxide. FEBS letters 579:2327-2333.

Barbazuk WB, Fu Y, and McGinnis KM. 2008. Genome-wide analyses of alternative splicing in plants: opportunities and challenges. Genome research 18:1381-1392.

Bhaduri A, Ravishankar R, and Sowdhamini R. 2004. Conserved spatially interacting motifs of protein superfamilies: application to fold recognition and function annotation of genome data. Proteins: Structure, Function, and Bioinformatics 54:657-670.

Bhardwaj PK, Mala D, and Kumar S. 2014. 2-Cys peroxiredoxin responds to low temperature and other cues in Caragana jubata, a plant species of cold desert of Himalaya. Molecular biology reports 41:2951-2961.

Campbell MA, Haas BJ, Hamilton JP, Mount SM, and Buell CR. 2006. Comprehensive analysis of alternative splicing in rice and comparative analyses with Arabidopsis. BMC genomics $7: 327$.

Cannon SB, Mitra A, Baumgarten A, Young ND, and May G. 2004. The roles of segmental and tandem gene duplication in the evolution of large gene families in Arabidopsis thaliana. BMC plant biology 4:10.

Cerveau D, Henri P, Blanchard L, and Rey P. 2019. Variability in the redox status of plant 2-Cys peroxiredoxins in relation to species and light cycle. Journal of experimental botany 70:5003-5016.

Cerveau D, Kraut A, Stotz HU, Mueller MJ, Couté Y, and Rey P. 2016. Characterization of the Arabidopsis thaliana 2-Cys peroxiredoxin interactome. Plant Science 252:30-41.

Chen Q, Han Y, Liu H, Wang X, Sun J, Zhao B, Li W, Tian J, Liang Y, and Yan J. 2018. Genome-wide association analyses reveal the importance of alternative splicing in diversifying gene function and regulating phenotypic variation in maize. The Plant Cell 30:1404-1423.

Cho C-W, Chung E, Heo J-E, So H-A, Choi H-K, Kim DH, Chung YS, Chae HZ, and Lee J-H. 2012. Molecular characterization of a 2-Cys peroxiredoxin induced by abiotic stress in mungbean. Plant Cell, Tissue and Organ Culture (PCTOC) 108:473-484.

Dietz K-J. 2011. Peroxiredoxins in plants and cyanobacteria. Antioxidants \& redox signaling 15:1129-1159.

Dietz K-J, Jacob S, Oelze M-L, Laxa M, Tognetti V, de Miranda SMN, Baier M, and Finkemeier I. 2006. The function of peroxiredoxins in plant organelle redox metabolism. Journal of experimental botany 57:1697-1709.

Peer] reviewing PDF | (2019:12:44008:5:0:NEW 6 Dec 2020) 
703

704

705

706

707

708

709

710

711

712

713

714

715

716

717

718

719

720

721

722

723

724

725

726

727

728

729

730

731

732

733

734

735

736

737

738

739

740

741

742

Ding M, Chen J, Jiang Y, Lin L, Cao Y, Wang M, Zhang Y, Rong J, and Ye W. 2015. Genomewide investigation and transcriptome analysis of the WRKY gene family in Gossypium. Molecular Genetics and Genomics 290:151-171.

Du X, Huang G, He S, Yang Z, Sun G, Ma X, Li N, Zhang X, Sun J, and Liu M. 2018. Resequencing of 243 diploid cotton accessions based on an updated A genome identifies the genetic basis of key agronomic traits. Nature genetics 50:796-802.

Emanuelsson O, Brunak S, Von Heijne G, and Nielsen H. 2007. Locating proteins in the cell using TargetP, SignalP and related tools. Nature protocols 2:953.

Fichman Y, Koncz Z, Reznik N, Miller G, Szabados L, Kramer K, Nakagami H, Fromm H, Koncz C, and Zilberstein A. 2018. SELENOPROTEIN O is a chloroplast protein involved in ROS scavenging and its absence increases dehydration tolerance in Arabidopsis thaliana. Plant Science 270:278-291.

Filichkin SA, Priest HD, Givan SA, Shen R, Bryant DW, Fox SE, Wong W-K, and Mockler TC. 2010. Genome-wide mapping of alternative splicing in Arabidopsis thaliana. Genome research 20:45-58.

Finkemeier I, Goodman M, Lamkemeyer P, Kandlbinder A, Sweetlove LJ, and Dietz K-J. 2005. The mitochondrial type II peroxiredoxin $\mathrm{F}$ is essential for redox homeostasis and root growth of Arabidopsis thaliana under stress. Journal of Biological Chemistry 280:1216812180.

Finn RD, Bateman A, Clements J, Coggill P, Eberhardt RY, Eddy SR, Heger A, Hetherington K, Holm L, and Mistry J. 2014. Pfam: the protein families database. Nucleic acids research 42:D222-D230.

Finn RD, Mistry J, Tate J, Coggill P, Heger A, Pollington JE, Gavin OL, Gunasekaran P, Ceric G, and Forslund K. 2009. The Pfam protein families database. Nucleic Acids Res 38:D211-222.

Goldmark PJ, Curry J, Morris CF, and Walker-Simmons M. 1992. Cloning and expression of an embryo-specific mRNA up-regulated in hydrated dormant seeds. Plant molecular biology 19:433-441.

Haddad R, and Japelaghi RH. 2015. Isolation of grape peroxiredoxin gene responding to abiotic stresses. Russian Journal of Plant Physiology 62:856-865.

Hall A, Nelson K, Poole LB, and Karplus PA. 2011. Structure-based insights into the catalytic power and conformational dexterity of peroxiredoxins. Antioxidants \& redox signaling 15:795-815.

Haslekås C, Grini PE, Nordgard SH, Thorstensen T, Viken MK, Nygaard V, and Aalen RB. 2003. ABI3 mediates expression of the peroxiredoxin antioxidant AtPER1 gene and induction by oxidative stress. Plant molecular biology 53:313-326.

Hofmann B, Hecht H, and Flohé L. 2002. Peroxiredoxins. Biol Chem 383:347-364.

Horling F, Baier M, and Dietz KJ. 2001. Redox-regulation of the expression of the peroxidedetoxifying chloroplast 2-Cys peroxiredoxin in the liverwort Riccia fluitans. Planta 214:304-313.

Peer) reviewing PDF | (2019:12:44008:5:0:NEW 6 Dec 2020) 
743

744

745

746

747

748

749

750

751

752

753

754

755

756

757

758

759

760

761

762

763

764

765

766

767

768

769

770

771

772

773

774

775

776

777

778

779

780

781

Horling F, König J, and Dietz K-J. 2002. Type II peroxiredoxin C, a member of the peroxiredoxin family of Arabidopsis thaliana: its expression and activity in comparison with other peroxiredoxins. Plant Physiology and Biochemistry 40:491-499.

$\mathrm{Hu}$ B, Jin J, Guo AY, Zhang H, and Gao G. 2014. GSDS 2.0: An upgraded gene feature visualization server. Bioinformatics 31:1296.

Hu X, Lu M, Li C, Liu T, Wang W, Wu J, Tai F, Li X, and Zhang J. 2011. Differential expression of proteins in maize roots in response to abscisic acid and drought. Acta Physiologiae Plantarum 33:p.2437-2446.

Huff RG, Bayram E, Tan H, Knutson ST, Knaggs MH, Richon AB, Nd SP, and Fetrow JS. 2005. Chemical and structural diversity in cyclooxygenase protein active sites. Chemistry \& Biodiversity 2:1533.

Iglesias Baena I. 2010. Caracterizacion bioquimica y molecular del sistema antioxidante peroxirredoxina-sulfirredoxina: Granada: Universidad de Granada.

Jaillon O, Aury J-M, Noel B, Policriti A, Clepet C, Casagrande A, Choisne N, Aubourg S, Vitulo $\mathrm{N}$, and Jubin C. 2007. The grapevine genome sequence suggests ancestral hexaploidization in major angiosperm phyla. nature 449:463.

Jing LW, Chen SH, Guo XL, Zhang H, and Zhao YX. 2006. Overexpression of a Chloroplast - located Peroxiredoxin Q Gene, SsPrxQ, Increases the Salt and Low - temperature Tolerance of Arabidopsis. Journal of Integrative Plant Biology 48:1244-1249.

Kang Y, and Udvardi M. 2012. Global regulation of reactive oxygen species scavenging genes in alfalfa root and shoot under gradual drought stress and recovery. Plant Signal Behav 7:539-543.

Kapuscinski J. 1995. DAPI: a DNA-specific fluorescent probe. Biotech Histochem 70:220-233. Biotechnic \& Histochemistry 70:220-233.

Khan-Malek R, and Wang Y. 2011. Statistical analysis of quantitative RT-PCR results. Drug Safety Evaluation: Springer, 227-241.

Knoops B, Loumaye E, and Eecken VVD. 2007. Evolution of the Peroxiredoxins. Sub Cellular Biochemistry 44:27.

Koch MA, Haubold B, and Mitchell-Olds T. 2000. Comparative evolutionary analysis of chalcone synthase and alcohol dehydrogenase loci in Arabidopsis, Arabis, and related genera (Brassicaceae). Molecular biology and evolution 17:1483-1498.

Kong W, Shiota S, Shi Y, Nakayama H, and Nakayama K. 2000. A novel peroxiredoxin of the plant Sedum lineare is a homologue of Escherichia coli bacterioferritin co-migratory protein (Bcp). Biochemical Journal 351:107-114.

König J, Baier M, Horling F, Kahmann U, Harris G, Schürmann P, and Dietz K-J. 2002. The plant-specific function of 2-Cys peroxiredoxin-mediated detoxification of peroxides in the redox-hierarchy of photosynthetic electron flux. Proceedings of the National Academy of Sciences 99:5738-5743.

Peer) reviewing PDF | (2019:12:44008:5:0:NEW 6 Dec 2020) 
782

783

784

785

786

787

788

789

790

791

792

793

794

795

796

797

798

799

800

801

802

803

804

805

806

807

808

809

810

811

812

813

814

815

816

817

818

819

820

821

Krzywinski M, Schein J, Birol I, Connors J, Gascoyne R, Horsman D, Jones SJ, and Marra MA. 2009. Circos: an information aesthetic for comparative genomics. Genome research 19:1639-1645.

Kumar S, Stecher G, and Tamura K. 2016. MEGA7: molecular evolutionary genetics analysis version 7.0 for bigger datasets. Molecular biology and evolution 33:1870-1874.

Lamkemeyer P, Laxa M, Collin V, Li W, and Dietz K-J. 2006. Peroxiredoxin Q of Arabidopsis thaliana is attached to the thylakoids and functions in context of photosynthesis. Plant Journal 45:968-981.

Lee ES, Kang CH, Park JH, and Lee SY. 2017. Physiological significance of plant peroxiredoxins (Prxs) and the structure-related and multi-functional biochemistry of Prx1. Antioxidants \& redox signaling:ars.2017.7400.

Lee TH, Kim SU, Yu SL, Kim SH, Park DS, Moon HB, Dho SH, Kwon KS, Kwon HJ, and Han YH. 2003. Peroxiredoxin II is essential for sustaining life span of erythrocytes in mice. Blood 101:5033-5038.

Lescot M, Déhais P, Thijs G, Marchal K, Moreau Y, Van de Peer Y, Rouzé P, and Rombauts S. 2002. PlantCARE, a database of plant cis-acting regulatory elements and a portal to tools for in silico analysis of promoter sequences. Nucleic acids research 30:325-327.

Li F, Fan G, Lu C, Xiao G, Zou C, Kohel RJ, Ma Z, Shang H, Ma X, and Wu J. 2015. Genome sequence of cultivated Upland cotton (Gossypium hirsutum TM-1) provides insights into genome evolution. Nature biotechnology 33:524-530.

Li J, Li L, and ZHANG G-f. 2013. A retrotransposon-like insertion-Characterization of Intron 1 in peroxiredoxin V from bay scallop Argopecten irradians. Marine Sciences 37:02.

Mastrangelo AM, Marone D, Laidò G, Leonardis AMD, and Vita PD. 2012. Alternative splicing: Enhancing ability to cope with stress via transcriptome plasticity. Plant Science 185186:0-49.

Mhamdi A, and Van Breusegem F. 2018. Reactive oxygen species in plant development. Development 145:dev164376.

Motamayor JC, Mockaitis K, Schmutz J, Haiminen N, Livingstone III D, Cornejo O, Findley SD, Zheng P, Utro F, and Royaert S. 2013. The genome sequence of the most widely cultivated cacao type and its use to identify candidate genes regulating pod color. Genome biology 14:r53.

Nelson KJ, Knutson ST, Soito L, Klomsiri C, Poole LB, and Fetrow JS. 2011. Analysis of the peroxiredoxin family: Using active-site structure and sequence information for global classification and residue analysis. Proteins-structure Function \& Bioinformatics 79:947964.

Nonn L, Berggren M, and Powis G. 2003. Increased Expression of Mitochondrial Peroxiredoxin3 (Thioredoxin Peroxidase-2) Protects Cancer Cells Against Hypoxia and Drug-Induced Hydrogen Peroxide-Dependent Apoptosis11CA52995 and CA772049. Molecular Cancer Research 1:682-689. 
822 Oláhová M, Taylor SR, Khazaipoul S, Wang J, Morgan BA, Matsumoto K, Blackwell TK, and

823

824

825

826

827

828

829

830

831

832

833

834

835

836

837

838

839

840

841

842

843

844

845

846

847

848

849

850

851

852

853

854

855

856

857

858

859

860

861

862
Veal EA. 2009. A redox-sensitive peroxiredoxin that is important for longevity has tissue- and stress-specific roles in stress resistance. Proceedings of the National Academy of Sciences 105:19839-19844.

Ouyang S, Zhu W, Hamilton J, Lin H, Campbell M, Childs K, Thibaud-Nissen F, Malek RL, Lee Y, and Zheng L. 2007. The TIGR Rice Genome Annotation Resource: improvements and new features. Nucleic acids research 35:D883-887. 10.1093/nar/gk1976

Paterson AH, Wendel JF, Gundlach H, Guo H, Jenkins J, Jin D, Llewellyn D, Showmaker KC, Shu S, and Udall J. 2012. Repeated polyploidization of Gossypium genomes and the evolution of spinnable cotton fibres. nature 492:423-427. 10.1038/nature11798

Pérez-Ruiz JM, Naranjo B, Ojeda V, Guinea M, and Cejudo FJ. 2017. NTRC-dependent redox balance of 2-Cys peroxiredoxins is needed for optimal function of the photosynthetic apparatus. Proceedings of the National Academy of Sciences of the United States of America:201706003.

Poulsen LR, Palmgren MG, and López-Marqués RL. 2016. Transient expression of P-type ATPases in tobacco epidermal cells. P-Type ATPases: Springer, 383-393.

Pulido P, Spínola MC, Kirchsteiger K, Guinea M, Pascual MB, Sahrawy M, Sandalio LM, Dietz K-J, González M, and Cejudo FJ. 2010. Functional analysis of the pathways for 2-Cys peroxiredoxin reduction in Arabidopsis thaliana chloroplasts. Journal of experimental botany 61:4043-4054.

Rauch HB, Patrick TL, Klusman KM, Battistuzzi FU, Mei W, Brendel VP, and Lal SK. 2013. Discovery and Expression Analysis of Alternative Splicing Events Conserved among Plant SR Proteins. Molecular Biology \& Evolution:3.

Reddy AS, Marquez Y, Kalyna M, and Barta A. 2013. Complexity of the Alternative Splicing Landscape in Plants. Plant Cell 25:3657-3683.

Romero-Puertas MC, Laxa M, Matte A, Zaninotto F, Finkemeier I, Jones AM, Perazzolli M, Vandelle E, Dietz K-J, and Delledonne M. 2007. S-nitrosylation of peroxiredoxin II E promotes peroxynitrite-mediated tyrosine nitration. The Plant Cell 19:4120-4130.

Salazar M, González E, Casaretto JA, Casacuberta JM, and Ruiz-Lara S. 2007. The promoter of the TLC1.1 retrotransposon from Solanum chilense is activated by multiple stress-related signaling molecules. Plant Cell Reports 26:1861-1868.

Soito L, Williamson C, Knutson ST, Fetrow JS, Poole LB, and Nelson KJ. 2011. PREX: PeroxiRedoxin classification indEX, a database of subfamily assignments across the diverse peroxiredoxin family. Nucleic acids research 39:D332-D337. $10.1093 / \mathrm{nar} / \mathrm{gkq} 1060$

Soltani Delroba N, Karamian R, and Ranjbar M. 2011. Interactive effects of salicylic acid and cold stress on activities of antioxidant enzymes in Glycyrrhiza glabra L. Journal of Herbal Drugs (An International Journal on Medicinal Herbs) 2:7-13.

Stenbaek A, Hansson A, Wulff RP, Hansson M, Dietz K-J, and Jensen PE. 2008. NADPHdependent thioredoxin reductase and 2-Cys peroxiredoxins are needed for the protection of $\mathrm{Mg}$-protoporphyrin monomethyl ester cyclase. FEBS letters 582:2773-2778.

PeerJ reviewing PDF | (2019:12:44008:5:0:NEW 6 Dec 2020) 
863 Sturn A, Quackenbush J, and Trajanoski Z. 2002. Genesis: cluster analysis of microarray data.

864

865

866

867

868

869

870

871

872

873

874

875

876

877

878

879

880

881

882

883

884

885

886

887

888

889

890

891

892

893

894

895

896

897

898

899

900

901

902

903 Bioinformatics 18:207-208. 10.1093/bioinformatics/18.1.207

Suyama M, Torrents D, and Bork P. 2006. PAL2NAL: robust conversion of protein sequence alignments into the corresponding codon alignments. Nucleic acids research 34:W609612. 10.1093/nar/gk1315

Syed NH, Kalyna M, Marquez Y, Barta A, and Brown JWS. 2012. Alternative splicing in plantscoming of age. Trends in Plant Science 17:616-623.

Tovar-Méndez A, Matamoros MA, Bustos-Sanmamed P, Dietz KJ, Cejudo FJ, Rouhier N, Sato S, and Becana TM. 2011. Peroxiredoxins and NADPH-Dependent Thioredoxin Systems in the Model Legume Lotus japonicus. Plant Physiology 156:1535-1547.

Vaseghi M-J, Chibani K, Telman W, Liebthal MF, Gerken M, Schnitzer H, Mueller SM, and Dietz K-J. 2018. The chloroplast 2-cysteine peroxiredoxin functions as thioredoxin oxidase in redox regulation of chloroplast metabolism. eLife 7:e38194.

Wang M, Tu L, Yuan D, Zhu D, Shen C, Li J, Liu F, Pei L, Wang P, and Zhao G. 2018. Reference genome sequences of two cultivated allotetraploid cottons, Gossypium hirsutum and Gossypium barbadense. Nature genetics.

Wang Y, Li J, and Paterson AH. 2013. MCScanX-transposed: detecting transposed gene duplications based on multiple colinearity scans. Bioinformatics:11.

Wang Y, Tang H, DeBarry JD, Tan X, Li J, Wang X, Lee T-h, Jin H, Marler B, and Guo H. 2012. MCScanX: a toolkit for detection and evolutionary analysis of gene synteny and collinearity. Nucleic acids research 40:e49. 10.1093/nar/gkr1293

Wenders F, Chainiaux F, Remacle J, Fisher AB, and Toussaint O. 2003. Retrovirally mediated overexpression of peroxiredoxin VI increases the survival of WI-38 human diploid fibroblasts exposed to cytotoxic doses of tert-butylhydroperoxide and UVB. Biogerontology 4:125-131.

Xing D, Chen X, Wu Y, Xu X, Chen Q, Li L, and Zhang C. 2019. Rapid prediction of the rewatering time point of Orychophragmus violaceus L. based on the online monitoring of electrophysiological indexes. Scientia Horticulturae 256:108642.

Xu J, Lan H, Fang H, Huang X, Zhang H, and Huang J. 2015. Quantitative proteomic analysis of the rice (Oryza sativa L.) salt response. PloS one 10:e120978. 10.1371/journal.pone.0120978

Xu Z, Wang M, Guo Z, Zhu X, and Xia Z. 2019. Identification of a 119-bp Promoter of the Maize Sulfite Oxidase Gene (ZmSO) That Confers High-Level Gene Expression and ABA or Drought Inducibility in Transgenic Plants. International journal of molecular sciences 20:3326.

Yoshida K, Hara A, Sugiura K, Fukaya Y, and Hisabori T. 2018. Thioredoxin-like2/2-Cys peroxiredoxin redox cascade supports oxidative thiol modulation in chloroplasts. Proceedings of the National Academy of Sciences 115:E8296-E8304.

Zhang D, Yang J-F, Gao B, Liu T-Y, Hao G-F, Yang G-F, Fu L-J, Chen M-X, and Zhang J. 2019. Identification, evolution and alternative splicing profile analysis of the splicing factor 30 (SPF30) in plant species. Planta 249:1997-2014. 10.1007/s00425-019-03146-X 
904 Zhang H, Ni Z, Chen Q, Guo Z, Gao W, Su X, and Qu Y. 2016. Proteomic responses of drought905 tolerant and drought-sensitive cotton varieties to drought stress. Molecular Genetics and $906 \quad$ Genomics 291:1293-1303.

907 Zhang T, Hu Y, Jiang W, Fang L, Guan X, Chen J, Zhang J, Saski CA, Scheffler BE, and Stelly

908 DM. 2015. Sequencing of allotetraploid cotton (Gossypium hirsutum L. acc. TM-1)

$909 \quad$ provides a resource for fiber improvement. Nature biotechnology 33:531-537.

$910 \quad 10.1038 /$ nbt.3207

911 Zhang Z, Li J, Zhao XQ, Wang J, Wong KS, and Yu J. 2006. KaKs_Calculator: Calculating Ka 912 and Ks Through Model Selection and Model Averaging. 4:- $0-263$.

913 Zhiguo E, Wang L, and Zhou J. 2013. Splicing and alternative splicing in rice and humans. Bmb $914 \quad$ Reports 46:439-447.

915 Zhou P, An Y, Wang Z, Du H, and Huang B. 2014. Characterization of gene expression 916 associated with drought avoidance and tolerance traits in a perennial grass species. PloS one 9:e103611.

918 
Figure 1

The conserved active sites of the $P R X$ protein sequence in cotton.

The multiple sequence alignment of $44 P R X$ proteins in cotton using ClustalW in MEGA7. The

active conserved sites and positions of conserved cysteinyl residues were marked with

columnar bars. The conserved cysteinyl residues marked by yellow bars. The mutation site is

marked by red bars.

\begin{tabular}{|c|c|c|}
\hline & & \\
\hline & & SYPENKHVKFLSDSSC \\
\hline \multirow[t]{5}{*}{ PRX } & RX11-D & PYVMRAWGKSYPENKHVKFLSDSSGAYVKTLGLEL \\
\hline & & YYMRA GKSYPFNKHVKFISDSSGAYVKTLGLE] \\
\hline & PRX1 & SYPENKHVKFLSD \\
\hline & GaPRX3 & SLKHVPGFIEKAAEFKSKGINEIICISVNDPFVMKAWAKTYPENKDVKFLADGSATYTHTLGLQLDLS \\
\hline & & CSLKHVPGF IEKAAEFKSKG INE I ICISVNDPFVMKAWAKTYPENKDVKF LADGSATYTHTLGLQLDLS \\
\hline \multirow{2}{*}{ PRX } & GbPRX13-D & PT CSLKHVPGFIEKAAEFKSKG INE I IC I SVNDPFVMKAWAKTYPENKDVKFLADGSATYTHTLGLQLDLSI \\
\hline & & IVPGFIEK \\
\hline \multirow[t]{7}{*}{ IIB } & & CSLKHVPGFIEKAGELKSKGVDEII I ISVNDPFVMKAWAKTYPENKDVKFLADGS \\
\hline & & VPGFIEKAGELKSKGVDEIICISY \\
\hline & $\mathrm{X} 7$ & GKKVI IFGVPGAFTPT SLKHVPGF IEKAGELKSKGVDE I I I SVNDPFVMKAWAKTYPENKDVKFLADGSAT \\
\hline & & CSLKHVPGF IEKAGELKSKGVDE I I I ISVNDPFVMKAWTKTYPENKDVKFLADGSAT? \\
\hline & & CSLKHVPGFTFKAGELKSKGVDEITCTSVI \\
\hline & & KVIIFGVPGAFIPTCSLKHVPGFIEKAGELKSKGVDEIICISV \\
\hline & & SQKHLPGFVEKSGE LKAKGVNT IACVSVNDAFVMRAW KENLG IKDEVLLLSDGNGEFTKKI \\
\hline \multirow{6}{*}{$\begin{array}{l}\text { PRX } \\
\text { IIE }\end{array}$} & & SQKHLPGFVEKSGELKAKGVNT IA V SVNDAFVMRA WKENLG IKDEVLLLSDG \\
\hline & & CSQKHLPGFVEKSGELKAKGVNTIACVSVNDAF \\
\hline & & AVPGAFT PT CSQKHLPGFVEKSGELKAKGVNT IA VSVNDAFVMRAWKENLG IKDEVLLLSDG \\
\hline & & CSQKHLPGFVEKSGELKAKG \\
\hline & & SQKHLPGFVEKSGELKAKGVNTIACVSVI \\
\hline & & :[68]FKGKKVVIF \\
\hline \multirow{4}{*}{$\begin{array}{l}\text { PRX } \\
\text { IIF }\end{array}$} & & VAI \\
\hline & & TGV SQQHVPSYKKSI DKFKAKRIDSVICVA INDPYVMNA ADKL \\
\hline & & SQQHVPSYKKNI DKFKAKGIDSVICVAVNDPYVMNAWADKLQANDVIEFYGDF \\
\hline & & SQQHVPSYKKNIDKFKAKG \\
\hline & & \\
\hline & & TK-QACAFRDSYEKFK-KAGAEVIGISVDS \\
\hline & & TK-QACAFRDSYEKFK-KAGAEVIGISVDSAESHKN AKKYRLPFTLLSDEGNK \\
\hline \multirow[t]{4}{*}{ PRXQ } & & CTK-QACAFRDSYEKFK-KAGAEVIGISVDSAESHKNEAKKYRLPFTLLSDEGNKVR \\
\hline & & \\
\hline & & SYEKFK-KAGAEVIGISVDS \\
\hline & & FY PADET PGCTK-QACAFRDSYEKFK-KAGAEVIGISVDSAESHKN AKKYRLPFTLLSDEGNKVRKEWGVPSDLFGTI \\
\hline \multirow{5}{*}{$\begin{array}{l}\text { 2-Cys } \\
\text { PRX }\end{array}$} & G & :[101] GKKYVILFFY LDF FV PT-EITAFSDRYEEFE-KLNTE ILGVS IDSVFSHLAWVQTDRKSGGLGDL- \\
- $[2$ \\
\hline & & $C D T=T M R=C$ \\
\hline & & :[101] GKKYVILFFY LDF FV PT-EITAFS DRYEEFE-KLNTE I LGVS IDSVF SHLAWVQTDRKSGGLGDL- $\backslash \backslash-[238]$ EVCPAGWKPC \\
\hline & & TFVCPT-EITAFSDRYEEFE-KLNTE ILGVS IDSVFSHLAWVQTDRKSGGLGDL- \\
-[238] EVCPAG \\
\hline & GhPRX2-A & :[101] GKKYVILFFY LDF FV PT-EITAFSDRYEEFE-KLNTE ILGVS IDSVF SHLAWVQTDRKSGGLGDL- \\
-[238] EVCPAGWKP \\
\hline \multirow{6}{*}{$\begin{array}{l}\text { 1-Cys } \\
\text { PRX }\end{array}$} & & : [28] FNNGWT I IFSH SDF PVCTT-ELGKMAAYLPEFE-KRG IKLLGF CDDVQSHKEW IKDVEAYTPGCKVAY PIVADPRREI IKQLNM \\
\hline & & CTT-ELGKMAAYLPEFE-KRGIKLLGF SCDDVQSHKEW IKDVEAYTPGCKVAYPIVADPRREI IKQLNMY \\
\hline & & :[28] FNNGWT I IFSH SDFTPV TT-ELGKMAAYLPEFE-KRGIKLLGF SCDDVQSHKEW IKDVEAYTPGCKVAYPIVADPRREI IKQLNM \\
\hline & & TT-ELGKMAAYLPEFE-KRGVK \\
\hline & & mo \\
\hline & & \\
\hline
\end{tabular}

Peer] reviewing PDF | (2019:12:44008:5:0:NEW 6 Dec 2020) 
Figure 2

Phylogenetic analysis of $P R X$ family members.

A maximum likelihood phylogenetic tree was constructed with $P R X$ protein sequences from

G. hirsutum, G. barbadense, G. arboreum, G. raimondii, Arabidopsis, Rice, Cacao, and Grapevine. Using the Poisson correction model, complete deletion and bootstrap analysis with 1000 replicates. 


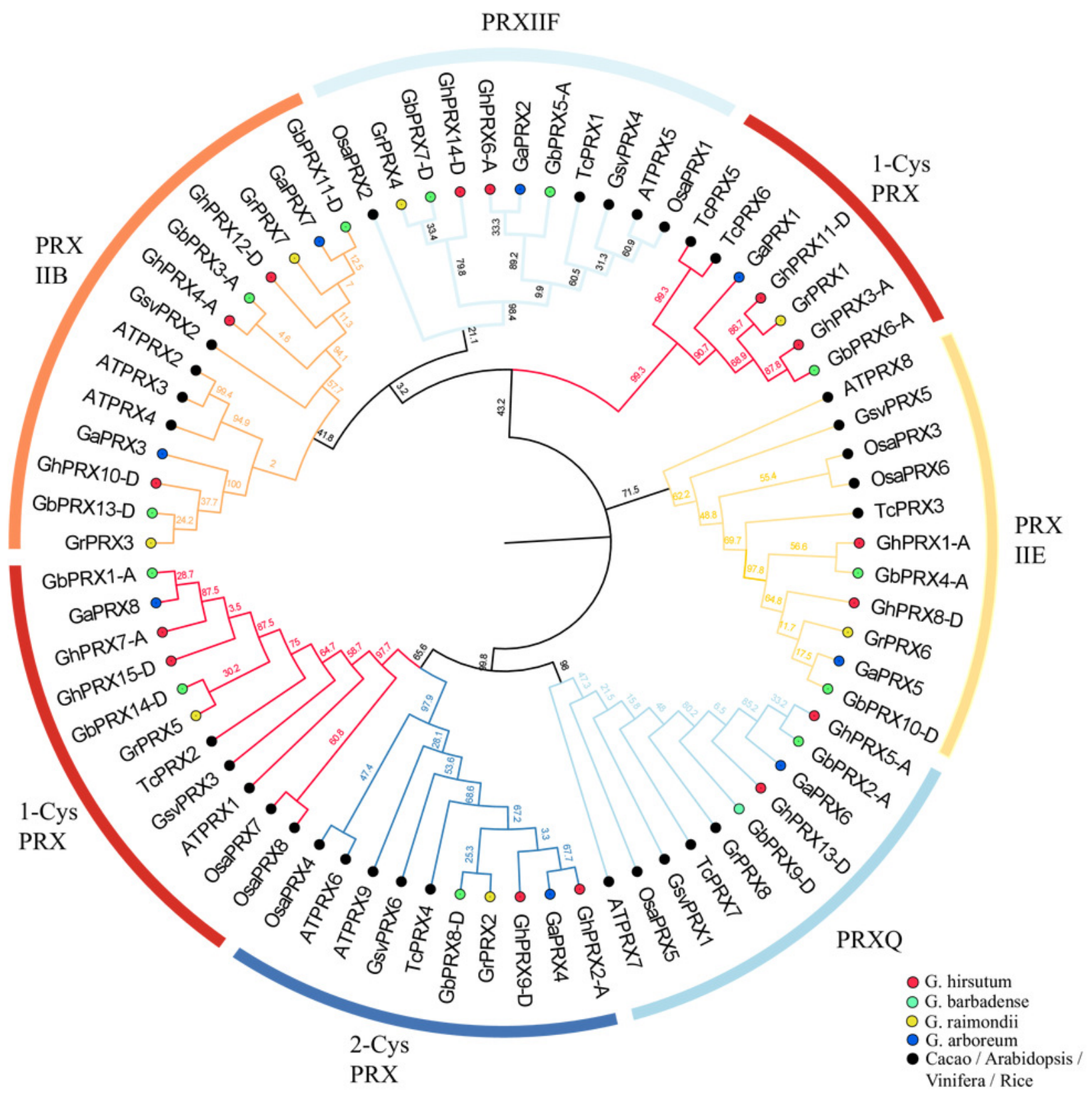


Figure 3

Phylogenetic tree, gene structure and conserved motif of $P R X s$ in cotton.

(A) Phylogenetic tree was constructed in MEGA7 using maximum likelihood (ML) method, the Poisson correction model, complete deletion and bootstrap analysis performed with 1000 replicates. (B) The exon/intron distribution of $P R X$ genes. (C) The distribution of domains in $P R X$ proteins.

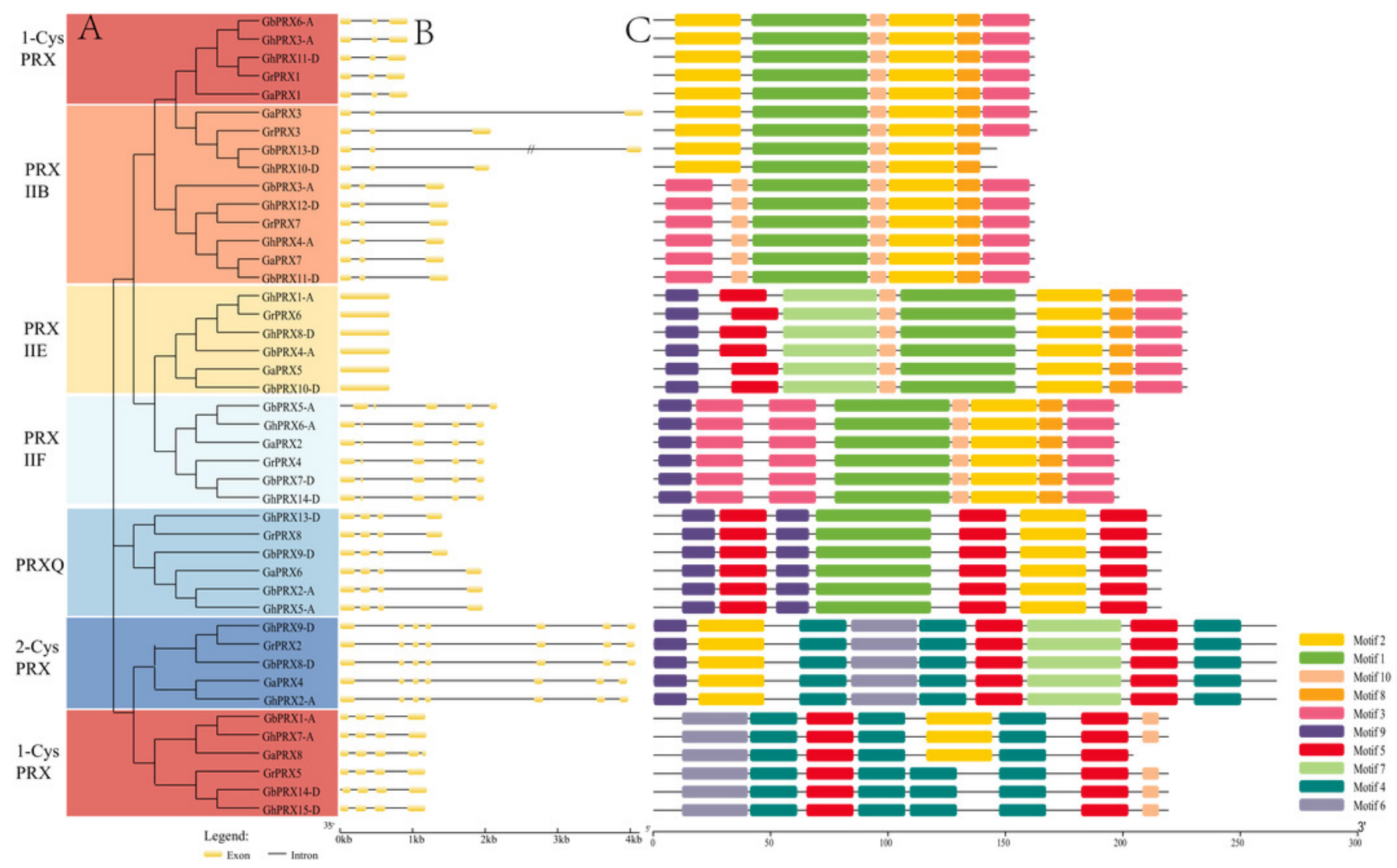




\section{Figure 4}

Chromosome physical mapping and duplication events of $P R X$ genes in the genomes of four cotton species.

Different color blocks represent different chromosomes, and the minimum scale represents 1000000 chromosome units. red links mark the physical site of genes on chromosomes. The homologous genes of the genes marked in black have been lost during the evolution of the species. The segmental duplication event occurred in the genes marked in blue. The homologous genes produced by segmental duplication events are connected by a blue curve, and the homologous genes produced by genomic polyploidization events are connected by a red curve. (A) Chromosomal physical mapping and duplication events of $P R X s$ in the $G$. hirsutum genome. (B) Chromosomal physical mapping and duplication events of PRXs in the G. barbadense genome. (C) Chromosomal physical mapping and duplication events of PRXS in the G. raimondii genome. (D) Chromosomal physical mapping and duplication events of $P R X s$ in the $G$. arboreum genome. 


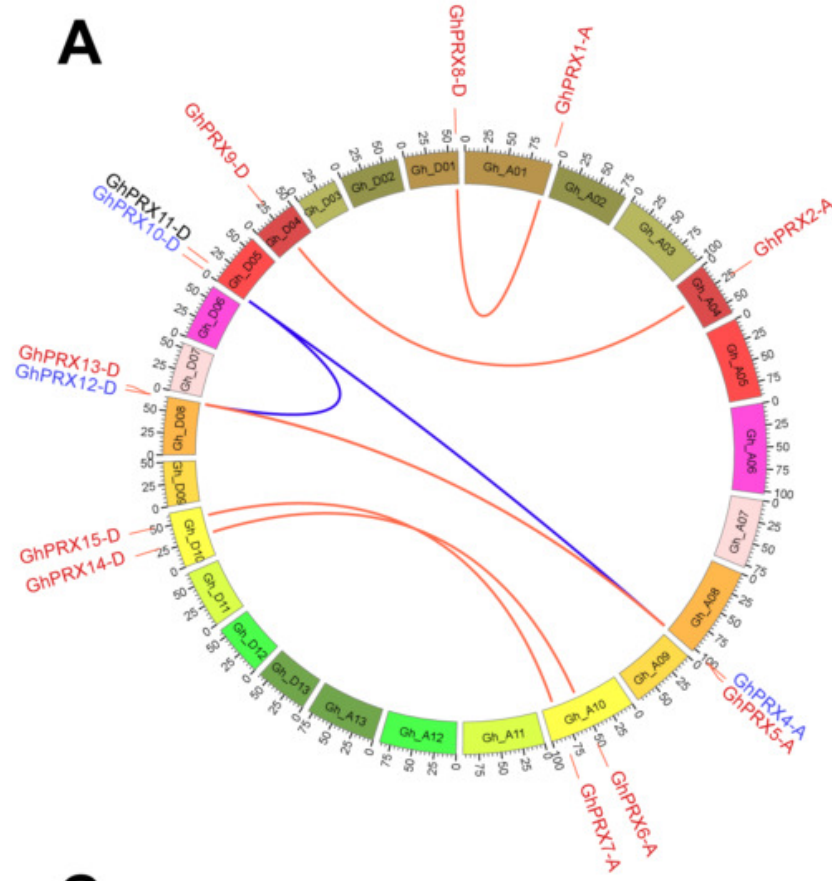

C

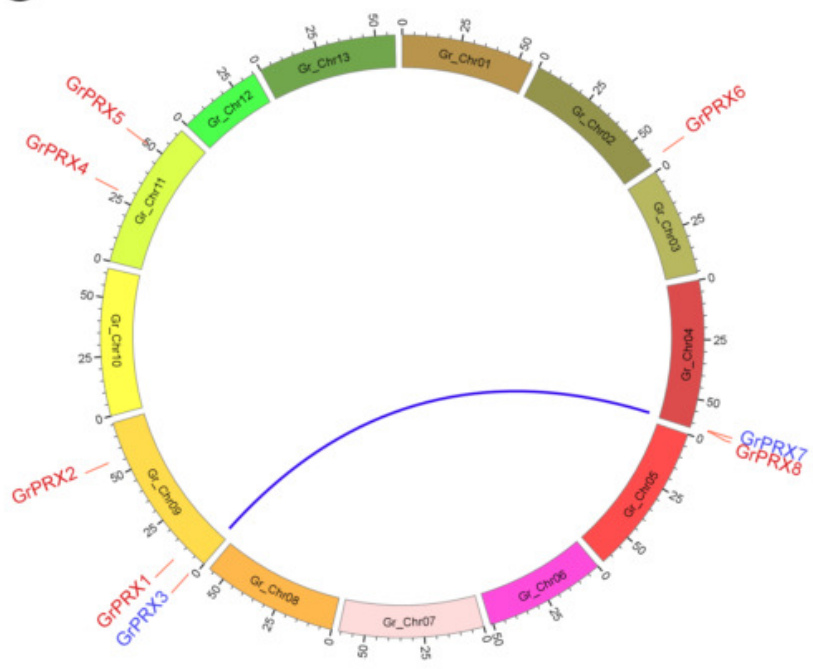

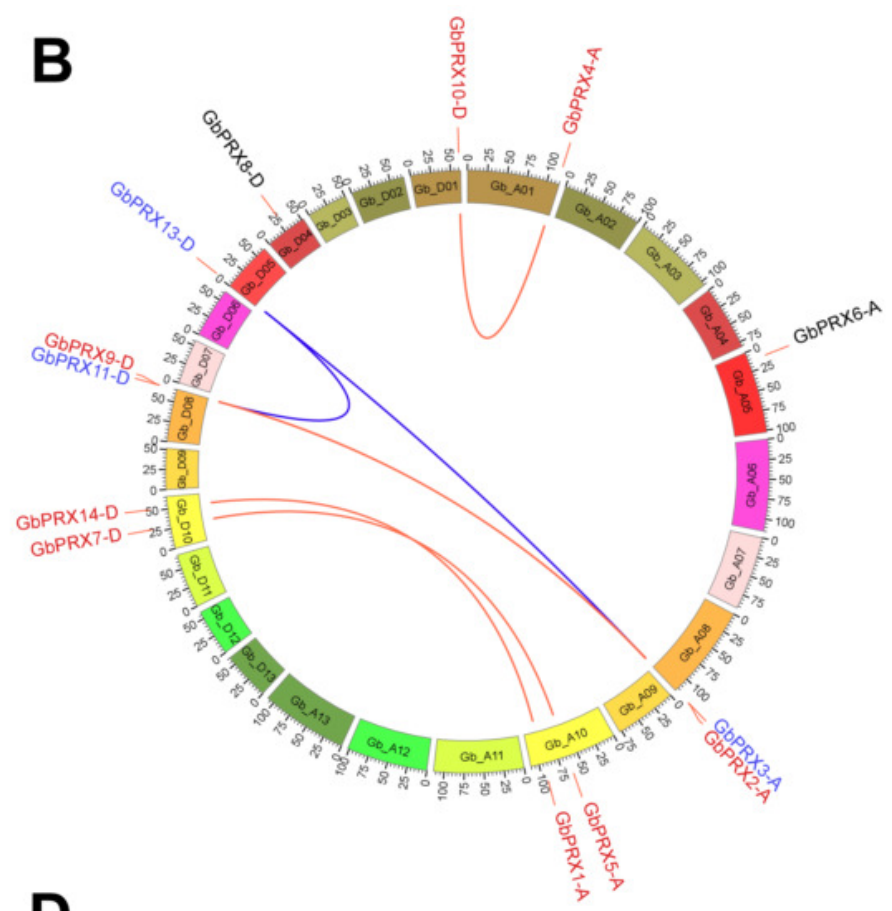

D

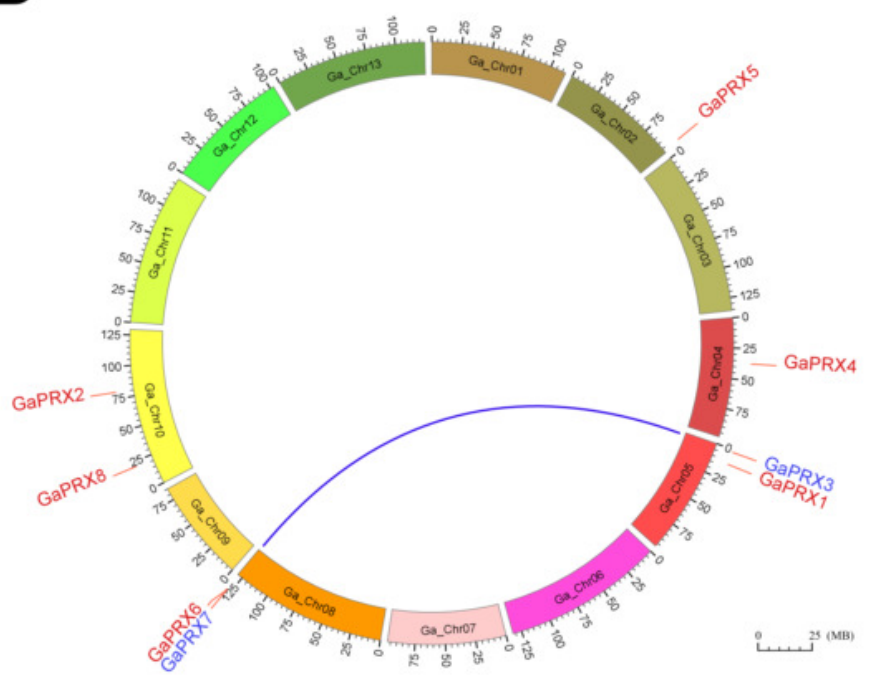




\section{Figure 5}

Cis-acting elements on the promoter of $P R X$ genes in cotton.

(A) Abiotic stress-related cis-acting elements. (B) Plant hormone-induced cis-acting elements.

(C) Cis-acting elements related to the growth and development of plants. 


\section{$A_{\text {abiotic stress-responsive elements }} \quad B_{\text {phytohormone responsive }} \quad C_{\text {plant growth and development }}$}

\begin{tabular}{|c|c|c|c|c|c|c|c|c|c|c|c|c|c|c|c|c|c|c|c|c|c|c|c|c|c|c|c|c|}
\hline & $\frac{1}{2}$ & & & & & & & & & 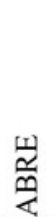 & & & & & & & 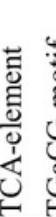 & & & 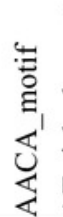 & 苛 & & & & & & & \\
\hline$\overline{\text { GhPRX1-A }}$ & 1 & 0 & 0 & 0 & 2 & 0 & 0 & 0 & 1 & 3 & 1 & 0 & 1 & 0 & 0 & 0 & 0 & 0 & 0 & 0 & 1 & 0 & 0 & 0 & 0 & 0 & 2 & 0 \\
\hline GhPRX2-A & 0 & 0 & 0 & 0 & 2 & 0 & 0 & 1 & 0 & 1 & 0 & 1 & 1 & 1 & 0 & 1 & 1 & 1 & 0 & 0 & 0 & 1 & 0 & 1 & 0 & 0 & 2 & 0 \\
\hline GhPRX3-A & 4 & 0 & 0 & 0 & 3 & 0 & 0 & 1 & 0 & 0 & 0 & 0 & 2 & 0 & 1 & 0 & 0 & 0 & 0 & 0 & 0 & 0 & 0 & 0 & 0 & 0 & 2 & 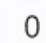 \\
\hline GhPRX4-A & 0 & 0 & 0 & 1 & 1 & 1 & 0 & 0 & 1 & 2 & 0 & 0 & 2 & 0 & 0 & 0 & 1 & 0 & 0 & 0 & 0 & 1 & 0 & 1 & 0 & 1 & 1 & 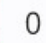 \\
\hline GhPRX5-A & 2 & 0 & 1 & 0 & 4 & 4 & 0 & 0 & 1 & 1 & 0 & 1 & 1 & 0 & 1 & 0 & 0 & 1 & 0 & 0 & 1 & 0 & 0 & U & 0 & 0 & 7 & \\
\hline GhPRX6-A & 1 & 0 & 0 & 0 & 4 & 1 & 0 & 2 & 1 & 0 & 2 & 1 & 0 & 0 & 1 & 0 & 2 & 1 & 1 & 0 & 0 & 0 & 0 & 0 & 1 & 0 & 2 & 0 \\
\hline GhPRX7-A & 1 & 0 & 0 & 1 & 7 & 0 & 0 & 0 & 0 & 1 & 0 & 0 & 6 & 0 & 0 & 0 & 0 & 0 & 0 & 0 & 0 & 0 & 0 & 0 & 0 & 0 & 2 & 0 \\
\hline GhPRX8-D & 1 & 0 & 0 & 0 & 3 & 0 & 0 & 0 & 0 & 1 & 0 & 1 & 4 & 0 & 0 & 0 & 1 & 1 & 0 & 0 & 0 & 0 & 0 & 0 & 0 & 0 & 1 & 0 \\
\hline GhPRX9-D & 1 & 0 & 1 & 0 & 5 & 1 & 0 & 1 & 1 & 2 & 1 & 0 & 3 & 0 & 0 & 0 & 0 & 0 & 0 & 0 & 0 & 0 & 0 & 0 & 1 & 0 & 0 & 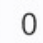 \\
\hline GhPRX10-D & 0 & 0 & 0 & 2 & 1 & 1 & 0 & 1 & 1 & 3 & 0 & 0 & 1 & 0 & 0 & 0 & 0 & 0 & 1 & 0 & 0 & 0 & 1 & 1 & 0 & 0 & 3 & 0 \\
\hline GhPRX11-D & 4 & 0 & 0 & 0 & 1 & 0 & 1 & 1 & 0 & 3 & 0 & 0 & 3 & 0 & 0 & 0 & 0 & 0 & 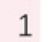 & 0 & 0 & 0 & 1 & 1 & 0 & 0 & 2 & 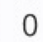 \\
\hline GhPRX12-D & 0 & 0 & 0 & 1 & 2 & 1 & 0 & 0 & 0 & 3 & 0 & 1 & 3 & 0 & 0 & 0 & 0 & 1 & 1 & 0 & 0 & 0 & 0 & 1 & 0 & 0 & 2 & 0 \\
\hline GhPRX13-D & 2 & 0 & 1 & 1 & 5 & 4 & 0 & 0 & 2 & 2 & 0 & 0 & 1 & 0 & 1 & 0 & 0 & 0 & 0 & 0 & 1 & 0 & 0 & 0 & 0 & 0 & 9 & 0 \\
\hline GhPRX14-D & 1 & 0 & 0 & 0 & 3 & 0 & 1 & 0 & 1 & 3 & 0 & 0 & 1 & 0 & 0 & 0 & 0 & 0 & 1 & 0 & 0 & 0 & 0 & 1 & 0 & 0 & 2 & 0 \\
\hline GhPRX15-D & 2 & 0 & 0 & 1 & 4 & 0 & 1 & 0 & 0 & 3 & 0 & 1 & 3 & 0 & 0 & 0 & 0 & 1 & 1 & 0 & 0 & 0 & 0 & 1 & 0 & 0 & 2 & 0 \\
\hline GbPRX4-A & 1 & 0 & 0 & 0 & 2 & 0 & 0 & 0 & 1 & 2 & 0 & 0 & 2 & 0 & 0 & 0 & 1 & 0 & 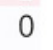 & 0 & 0 & 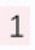 & 0 & 1 & 0 & 1 & 2 &  \\
\hline GbPRX6-A & 4 & 0 & 0 & 0 & 3 & 0 & 0 & 1 & 0 & 1 & 0 & 1 & 5 & 0 & 0 & 0 & 1 & 1 & 0 & 0 & 0 & 0 & 0 & 1 & 0 & 0 & 1 & 0 \\
\hline GbPRX3-A & 0 & 0 & 0 & 1 & 1 & 0 & 0 & 0 & 0 & 3 & 1 & 0 & 1 & 0 & 0 & 0 & 0 & 0 & 0 & 0 & 1 & 0 & 0 & 0 & 0 & 0 & 3 & 0 \\
\hline GbPRX2-A & 2 & 0 & 1 & 0 & 4 & 2 & 0 & 0 & 1 & 1 & 0 & 1 & 1 & 1 & 0 & 1 & 1 & 1 & 0 & 0 & 0 & 0 & 0 & 1 & 0 & 0 & 3 & 0 \\
\hline GbPRX5-A & 1 & 0 & 0 & 0 & 3 & 2 & 0 & 2 & 1 & 0 & 0 & 1 & 1 & 0 & 1 & 0 & 0 & 1 & 0 & 1 & 0 & 0 & 0 & 0 & 0 & 0 & 2 & 0 \\
\hline GbPRX1-A & 1 & 0 & 0 & 1 & 7 & 0 & 0 & 0 & 0 & 0 & 2 & 1 & 0 & 0 & 1 & 0 & 1 & 1 &  & 0 & 0 &  & 0 & 0 & 1 & 0 & 2 & + \\
\hline GbPRX10-D & 1 & 0 & 0 & 0 & 3 & 1 & 0 & 0 & 0 & 3 & 0 & 0 & 1 & 0 & 0 & 0 & 1 & 0 & 0 & 0 & 0 & 0 & 0 & 1 & 0 & 1 & 1 & 0 \\
\hline GbPRX8-D & 1 & 0 & 1 & 0 & 5 & 0 & 1 & 1 & 1 & 0 & 0 & 0 & 3 & 0 & 0 & 0 & 0 & 0 & 0 & 0 & 0 & 0 & 0 & 0 & 0 & 0 & 0 & 0 \\
\hline GbPRX13-D & 1 & 0 & 0 & 1 & 2 & 1 & 0 & 0 & 1 & 2 & 1 & 0 & 4 & 0 & 0 & 0 & 0 & 0 & 0 & 0 & 0 & 0 & 0 & 0 & 0 & 0 & 3 & 0 \\
\hline $\mathrm{Gbl}$ & 0 & 1 & 0 & 2 & 1 & 0 & 0 & 0 & 0 & 0 & 0 & 1 & 2 & 0 & 1 & 0 & 2 & 1 & 0 & 0 & 0 & 0 & 0 & 0 & 0 & 0 & 2 & 0 \\
\hline GbPRX9-D & 2 & 0 & 1 & 1 & 3 & 2 & 0 & 0 & 3 & 1 & 0 & 0 & 6 & 0 & 0 & 0 & 0 & 0 & 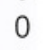 & 0 & 0 & 0 & 0 & 0 & 0 & 0 & 2 & 0 \\
\hline GbPRX7-D & 1 & 0 & 0 & 1 & 2 & 0 & 1 & 0 & 1 & 1 & 0 & 1 & 1 & 0 & 1 & 0 & 0 & 1 & 0 & 0 & 1 & 0 & 0 & 0 & 0 & 0 & 7 & 0 \\
\hline GbPRX14-D & 2 & 0 & 0 & 1 & 4 & 0 & 1 & 0 & 0 & 3 & 0 & 0 & 2 & 0 & 0 & 0 & 0 & 0 & 0 & 0 & 0 & 2 & 0 & 1 & 0 & 1 & 1 & 0 \\
\hline GaPRX5 & 1 & 0 & 0 & 0 & 0 & 0 & 0 & 0 & 1 & 0 & 0 & 1 & 1 & 0 & 1 & 0 & 0 & 1 & 0 & 1 & 0 & 0 & 0 & 0 & 0 & 0 & 2 & 0 \\
\hline GaPRX4 & 0 & 0 & 0 & 1 & 0 & 0 & 0 & 1 & 1 & 0 & 2 & 1 & 0 & 0 & 1 & 0 & 1 & 1 & 0 & 0 & 0 & 0 & 0 & 0 & 1 & 0 & 1 & 1 \\
\hline GaPRX3 & 1 & 0 & 0 & 2 & 0 & 1 & 0 & 1 & 2 & 1 & 0 & 0 & 0 & 0 & 0 & 0 & 1 & 0 & 0 & 0 & 0 & 0 & 0 & 1 & 1 & 1 & 2 & 0 \\
\hline GaPRX1 & 4 & 0 & 0 & 0 & 0 & 0 & 0 & 1 & 0 & 0 & 0 & 0 & 3 & 0 & 0 & 0 & 0 & 0 & 0 & 0 & 0 & 0 & 0 & 0 & 0 & 0 & 4 & 0 \\
\hline GaPRX7 & 0 & 0 & 0 & 1 & 0 & 1 & 0 & 0 & 1 & 2 & 1 & 0 & 4 & 0 & 0 & 0 & 0 & 0 & 0 & 0 & 0 & 0 & 0 & 0 & 0 & 0 & 3 & 0 \\
\hline GaPRX6 & 2 & 0 & 1 & 0 & 0 & 4 & 0 & 0 & 1 & 0 & 0 & 1 & 1 & 0 & 1 & 0 & 2 & 1 & 0 & 0 & 0 & 0 & 0 & 0 & 0 & 0 & 2 & 0 \\
\hline GaPRX8 & 1 & 0 & 0 & 1 & 0 & 0 & 0 & 0 & 1 & 1 & 0 & 0 & 6 & 0 & 0 & 0 & 0 & 0 & 0 & 0 & 0 & 0 & 0 & 0 & 0 & 0 & 2 & 0 \\
\hline GaPRX2 & 1 & 0 & 0 & 0 & 0 & 1 & 0 & 2 & 0 & 0 & 2 & 1 & 0 & 0 & 0 & 0 & 1 & 1 & 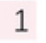 & 0 & 0 & 0 & 0 & 0 & 1 & 0 & 1 & U \\
\hline GrPRX6 & 1 & 0 & 0 & 0 & 4 & 0 & 0 & 0 & 0 & 0 & 0 & 1 & 1 & 0 & 1 & 0 & 0 & 1 & 0 & 1 & 0 & 0 & 0 & 0 & 0 & 0 & 2 & 0 \\
\hline GrPRX7 & 0 & 1 & 0 & 1 & 1 & 2 & 0 & 0 & 0 & 0 & 0 & 0 & 1 & 0 & 1 & 0 & 0 & 0 & 0 & 0 & 1 & 0 & 0 & 0 & 0 & 0 & 8 & 0 \\
\hline GrPRX8 & 2 & 0 & 1 & 1 & 3 & 2 & 0 & 0 & 3 & 2 & 2 & 1 & 0 & 0 & 0 & 0 & 1 & 1 & 0 & 0 & 0 & 0 & 0 & 0 & 1 & 0 & 1 & 1 \\
\hline GrPRX3 & 2 & 1 & 0 & 1 & 2 & 0 & 0 & 1 & 1 & 3 & 0 & 0 & 0 & 0 & 0 & 0 & 1 & 0 & 0 & 0 & 0 & 0 & 0 & 1 & 0 & 1 & 2 & 0 \\
\hline GrPRX1 & 3 & 0 & 0 & 1 & 2 & 0 & 2 & 1 & 0 & 2 & 1 & 0 & 5 & 0 & 0 & 0 & 0 & 0 & 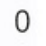 & 0 & 0 & ) & 0 & 0 & 0 & 0 & 3 & 0 \\
\hline GrPRX2 & 1 & 0 & 1 & 0 & 6 & 0 & 1 & 1 & 0 & 0 & 0 & 0 & 2 & 0 & 0 & 0 & 0 & 0 & 0 & 0 & 0 & 0 & 0 & U & 0 & 0 & 3 & 0 \\
\hline GrPRX4 & 1 & 0 & 1 & 0 & 4 & 0 & 1 & 0 & 1 & 1 & 0 & 1 & 0 & 0 & 1 & 0 & 0 & 1 & 0 & 0 & 0 & 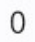 & 0 & 0 & 0 & 0 & 3 & 0 \\
\hline GrPRX5 & 2 & 0 & 0 & 0 & 5 & 0 & 2 & 0 & 0 & 3 & 0 & 1 & 3 & 0 & 0 & 1 & 0 & 1 & 1 & 0 & 0 & 0 & 0 & 1 & 0 & 0 & 1 & 0 \\
\hline
\end{tabular}


Figure 6

Analysis of cis-acting elements in the promoter region of Gh-PRX genes.

The promoter region has 1500 bp before the gene translation initiation site.

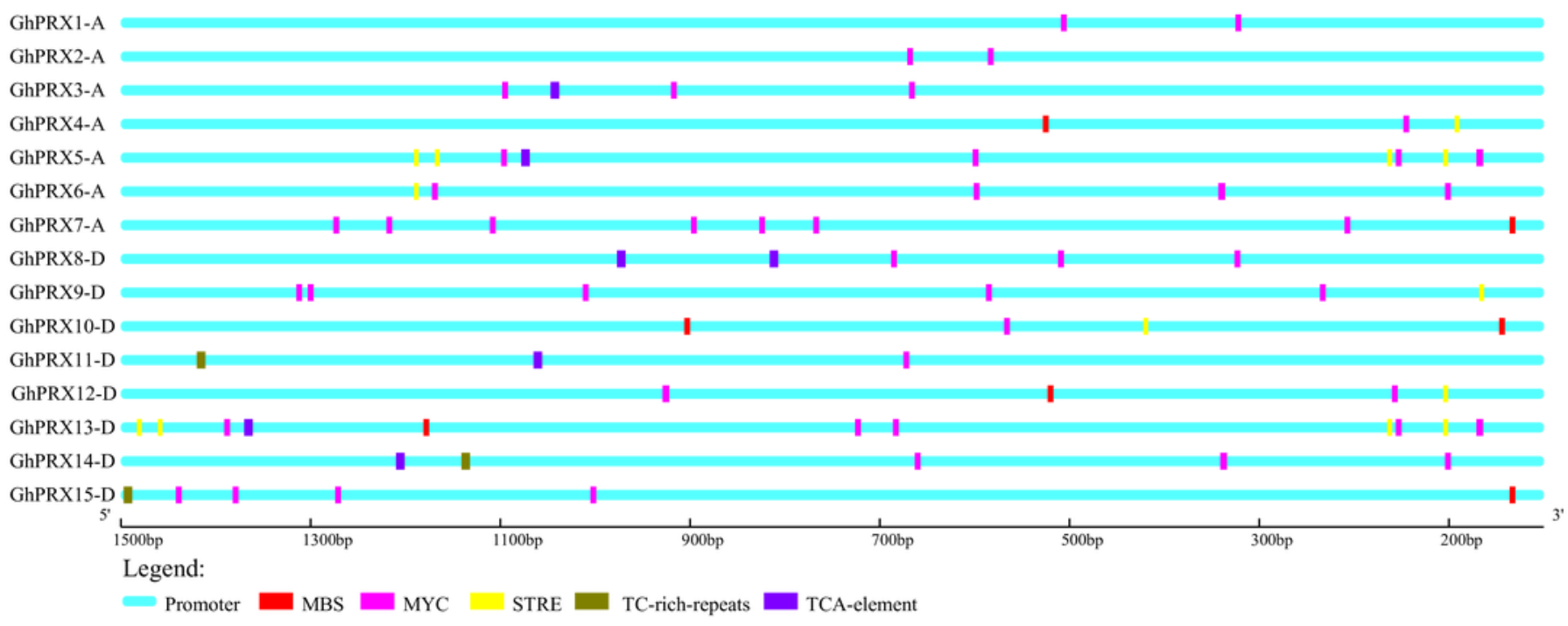




\section{Figure 7}

Expression patterns of Gh-PRX genes in G. hirsutum roots.

The $2^{-\Delta C T}$ method was used to analyze the expression patterns of $G h-P R X$ genes in $G$.

hirsutum roots. ( $2^{-\Delta C T}$ calculation steps: 1 . House-keeping gene homogenization sample difference: $\Delta C T=C t$ target gene - $\mathrm{Ct}$ house-keeping genes; 2 . Comparison of stress samples and control samples at $\mathrm{Oh}: \Delta \mathrm{Ct}=\Delta \mathrm{Ct}$ stress sample $-\Delta \mathrm{Ct}$ control sample; 3 . Calculation: Fold change $=2^{-\Delta C T}$ ). G. hirsutum seedlings were treated with drought, salt stress and SA hormone at the trefoil stage, and the expression patterns of $G h-P R X$ genes were identified by qRT-PCR. The blue strip column is the control, the orange strip column is $\mathrm{NaCl}$ stress, the gray bar column is SA stress, and the yellow bar column is drought stress. Using the cotton ubiquitin 7 gene as House-keeping gene, the statistical significant differences of the expression levels were show using the fold change values, all the values at all times were compared with the corresponding values at $0 \mathrm{~h}$. Results are the average of three replicates, and the error bars indicating standard deviations. 

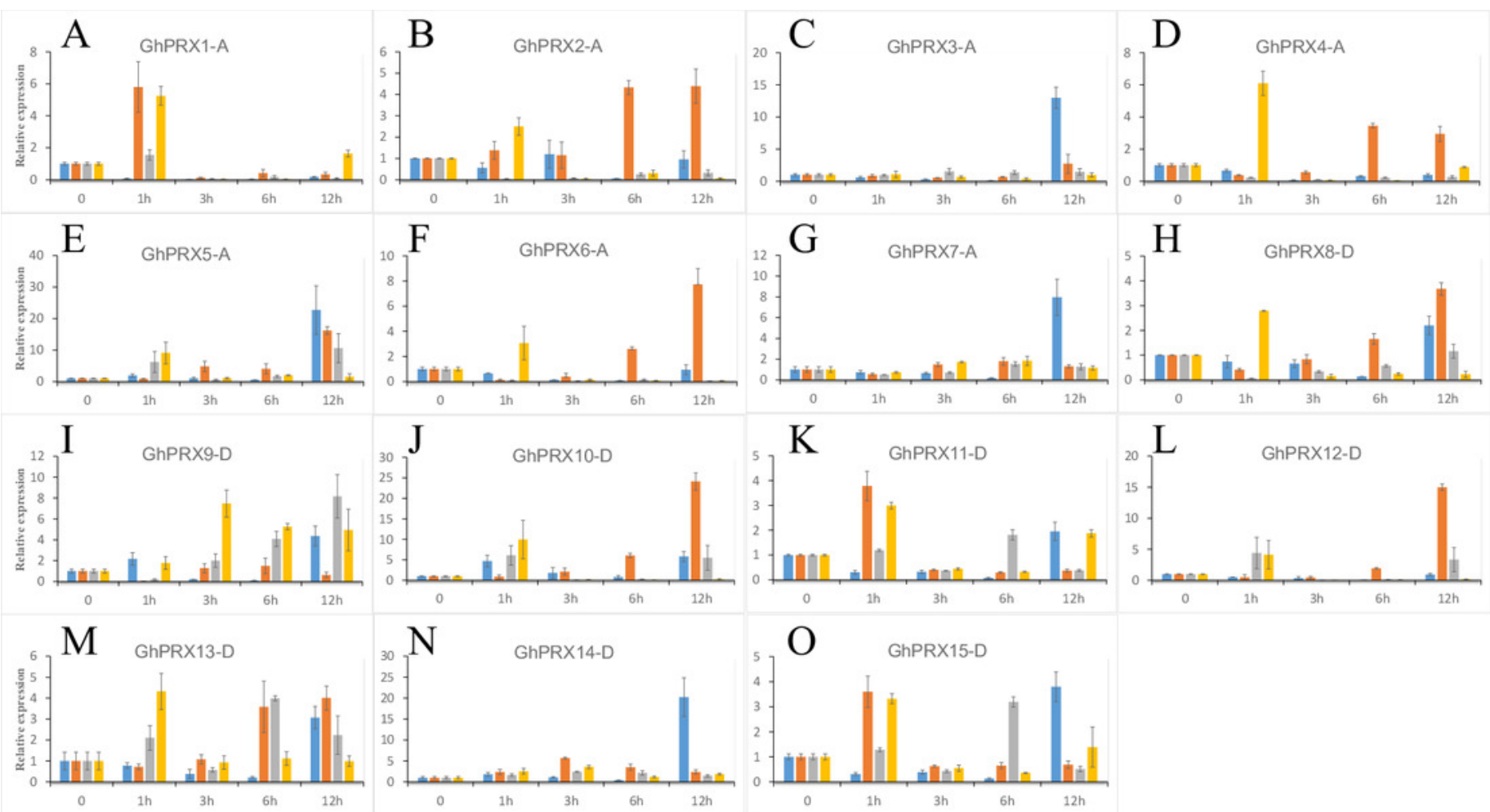


\section{Figure 8}

Expression patterns of Gh-PRX genes in G. hirsutum leaves.

The $2^{-\Delta C T}$ method was used to analyze the expression patterns of $G h-P R X$ genes in $G$.

hirsutum leaves. ( $2^{-\Delta C T}$ calculation steps: 1. House-keeping gene homogenization sample difference: $\Delta C T=C t$ target gene - $\mathrm{Ct}$ house-keeping genes; 2 . Comparison of stress samples and control samples at $0 \mathrm{~h}: \Delta \mathrm{Ct}=\Delta \mathrm{Ct}$ stress sample $-\Delta \mathrm{Ct}$ control sample; 3 . Calculation:

Fold change $\left.=2^{-\Delta C T}\right) . G$. hirsutum seedlings were treated with drought, salt stress and SA hormone at the trefoil stage, and the expression patterns of $G h-P R X$ genes were identified by qRT-PCR. The blue strip column is the control, the orange strip column is $\mathrm{NaCl}$ stress, the gray bar column is SA stress, and the yellow bar column is drought stress. Using the cotton ubiquitin 7 gene as House-keeping gene, the statistical significant differences of the expression levels were show using the fold change values, all the values at all times were compared with the corresponding values at $0 \mathrm{~h}$. Results are the average of three replicates, and the error bars indicating standard deviations. 

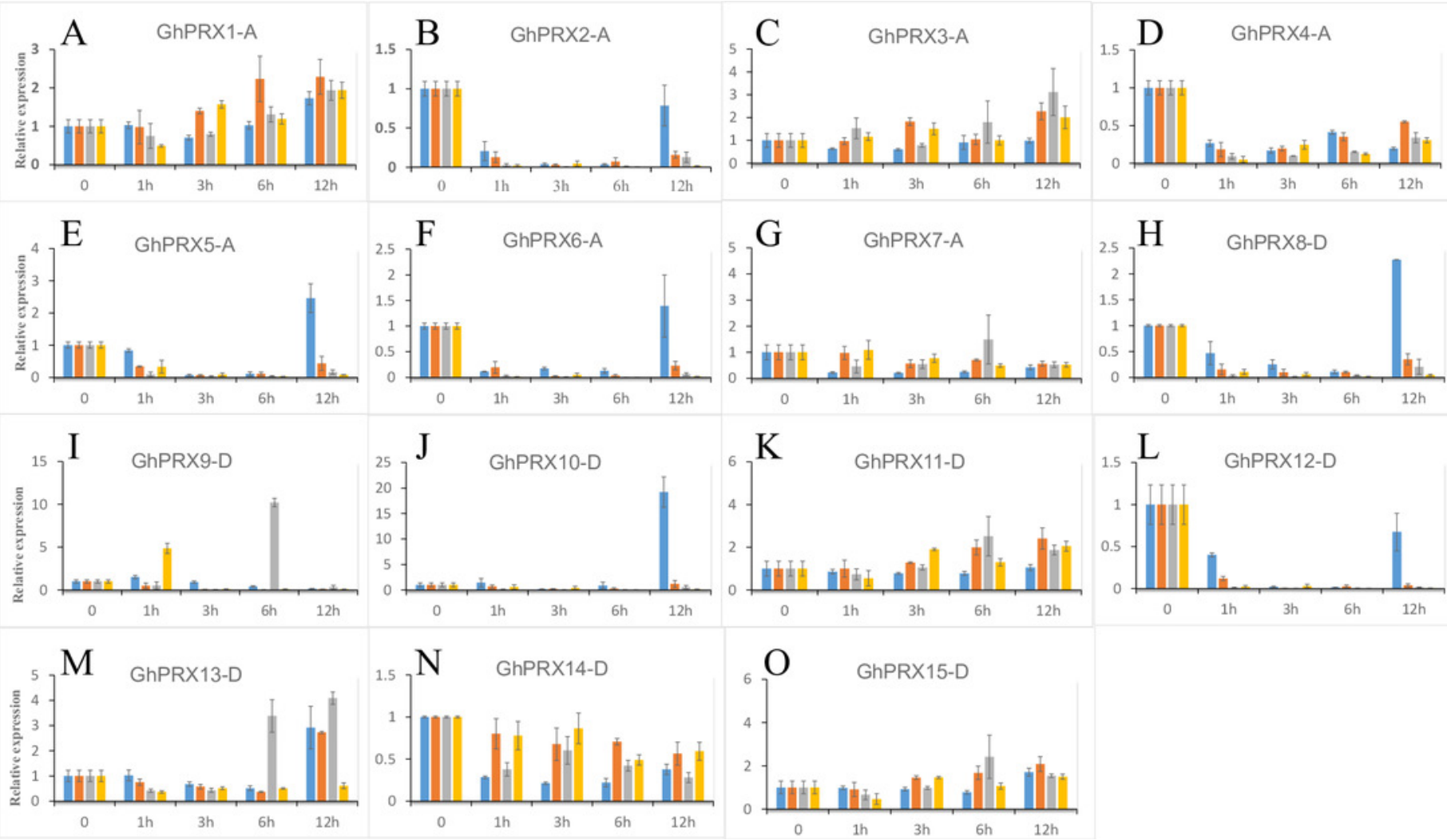


\section{Figure 9}

Analysis of tissue expression and alternative shearing profiles of $P R X$ genes.

(A) Expression patterns of $P R X s$ in different tissues and organs of G. hirsutum TM-1. The color represents Gh-PRX expression levels: Log2 (FPKM). (B) Agarose gel electrophoresis map of $P R X s$ in G. hirsutum sGK9708 leaves. (C) Agarose gel electrophoresis map of $P R X s$ in $G$. hirsutum roots. (D) Structural diagram of GhPRX14 alternative shearing transcripts. GhPRX14-D is the reference transcript of $G$. hirsutum TM-1. The DNA marker is the Trans2K DNA marker from TransGen. (E) Agarose gel electrophoresis map of GhPRX14-D in G. hirsutum leaves and roots.

A



D

GhPRX14-Leaf-ASI

GhPRX14-Leaf-AS2

GhPRX14-Root-AS

GhPRX14-Root-AS2

GhPRX14-Root-AS

Legend:
B

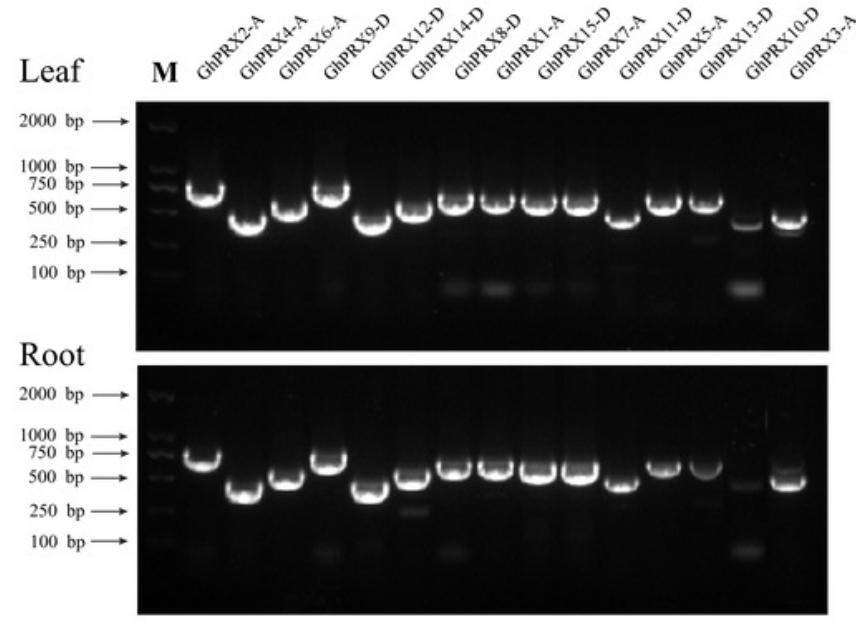

$\mathbf{E}$
$2000 \mathrm{bp} \rightarrow$
$1000 \mathrm{bp} \rightarrow$
$750 \mathrm{bp} \rightarrow$
$500 \mathrm{bp} \rightarrow-660$
$250 \mathrm{bp} \rightarrow$

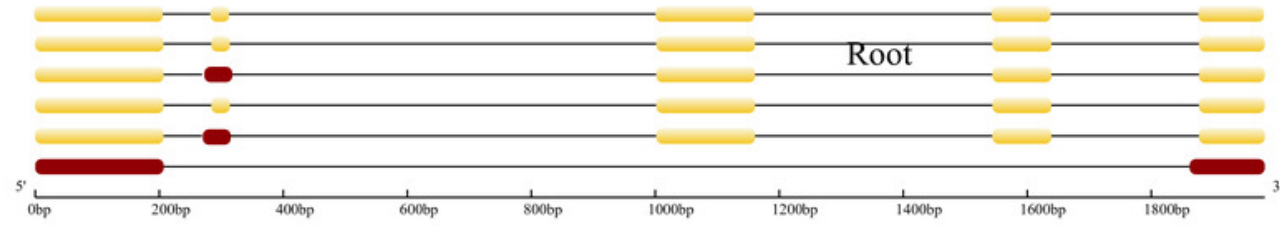

- Intron 


\section{Figure 10}

Subcellular localization map of $P R X$ proteins.

Subcellular localization map of $P R X$ proteins. (A-I) The protein fluorescence signals of the eGFP control, GhPRX4-A and GhPRX12-D are located on the cell membrane; (J-Q) The protein fluorescence signals of GhPRX7-A and GhPRX15-D are located on the cell membrane and nucleus; (R-00) The protein fluorescence signals of GhPRX1-A, GhPRX8-D, GhPRX2-A, GhPRX9-D, GhPRX6-A and GhPRX14-D are located on chloroplasts. GFP is a fluorescence signal excited by recombinant pcambia2300-eGFP (CAMBIA) transient expression vector, DAPI stains the nucleus, and chloroplast autofluorescence was obtained at $635 \mathrm{~nm}$ fluorescence receiving wavelength.
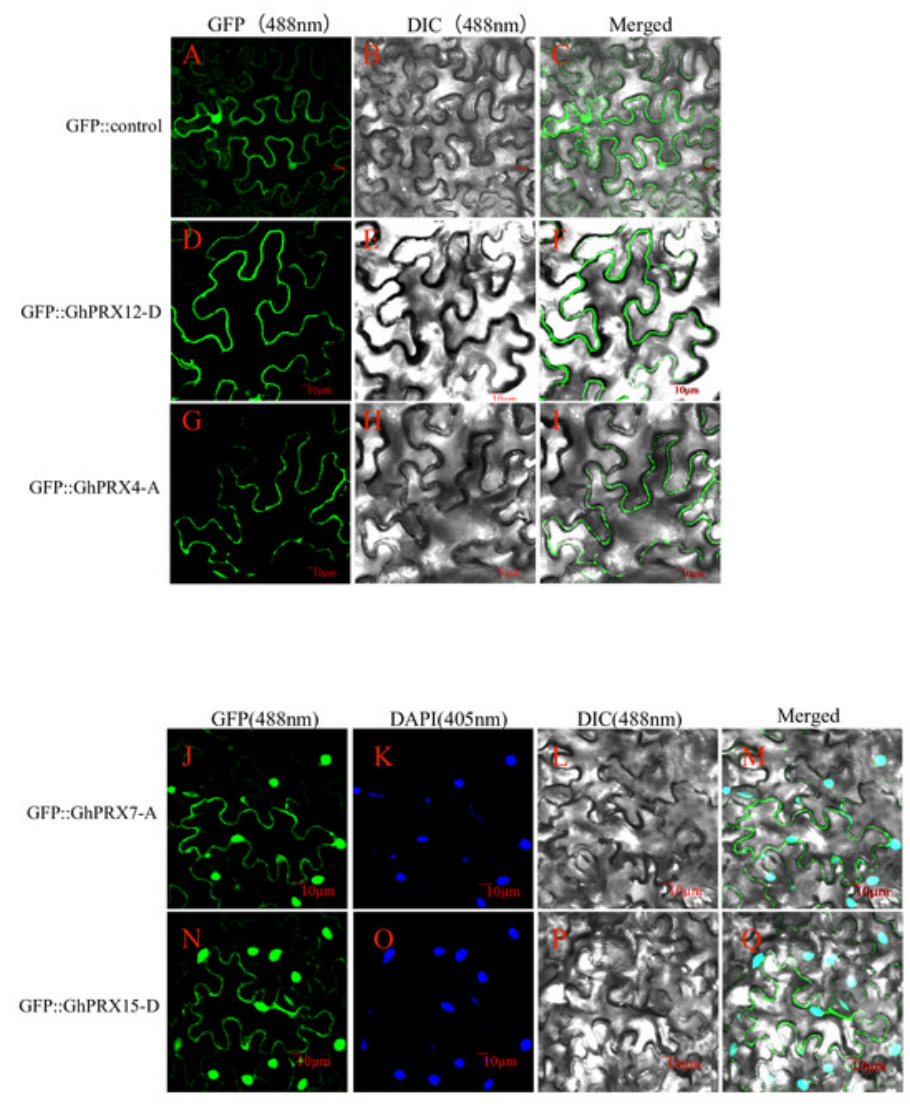

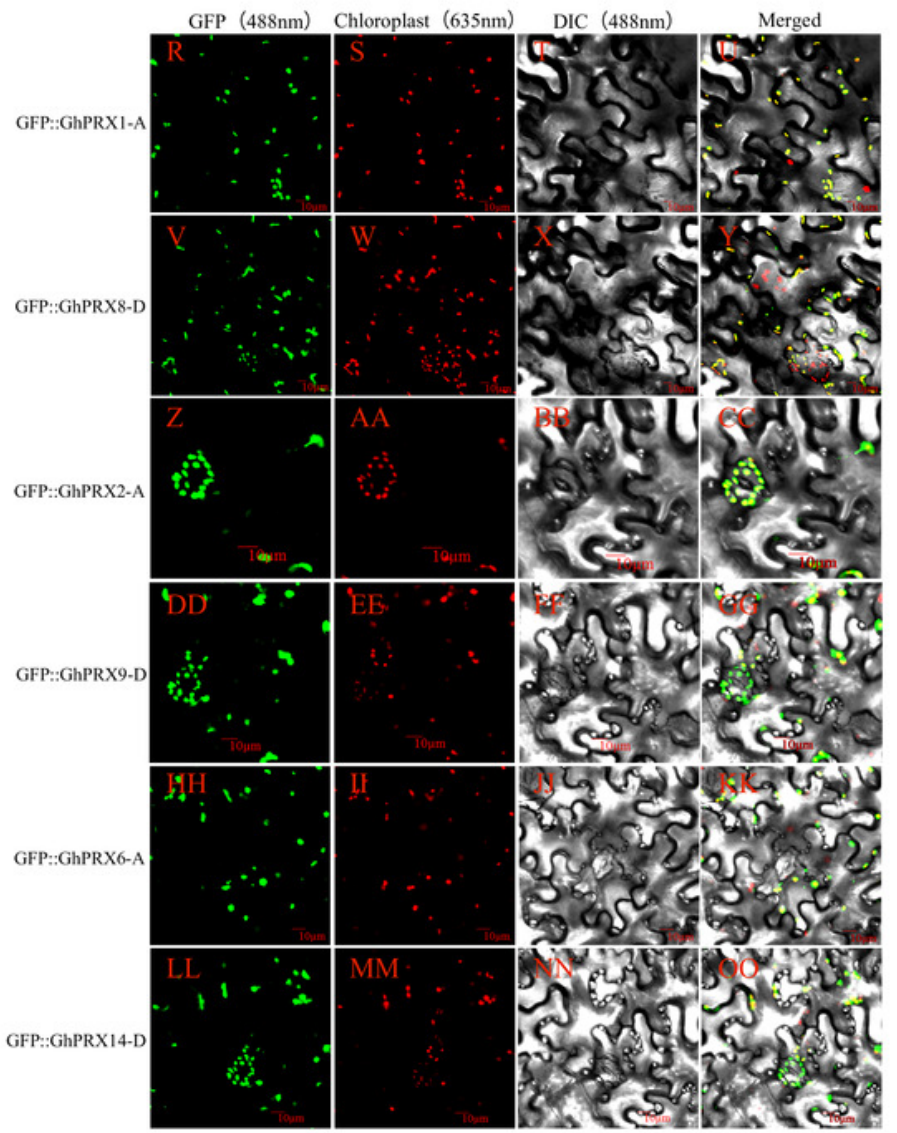




\section{Table $\mathbf{1}$ (on next page)}

The characteristics of the $P R X$ family genes in cotton. 
1 Table 1 The characteristics of the $P R X$ family genes in cotton

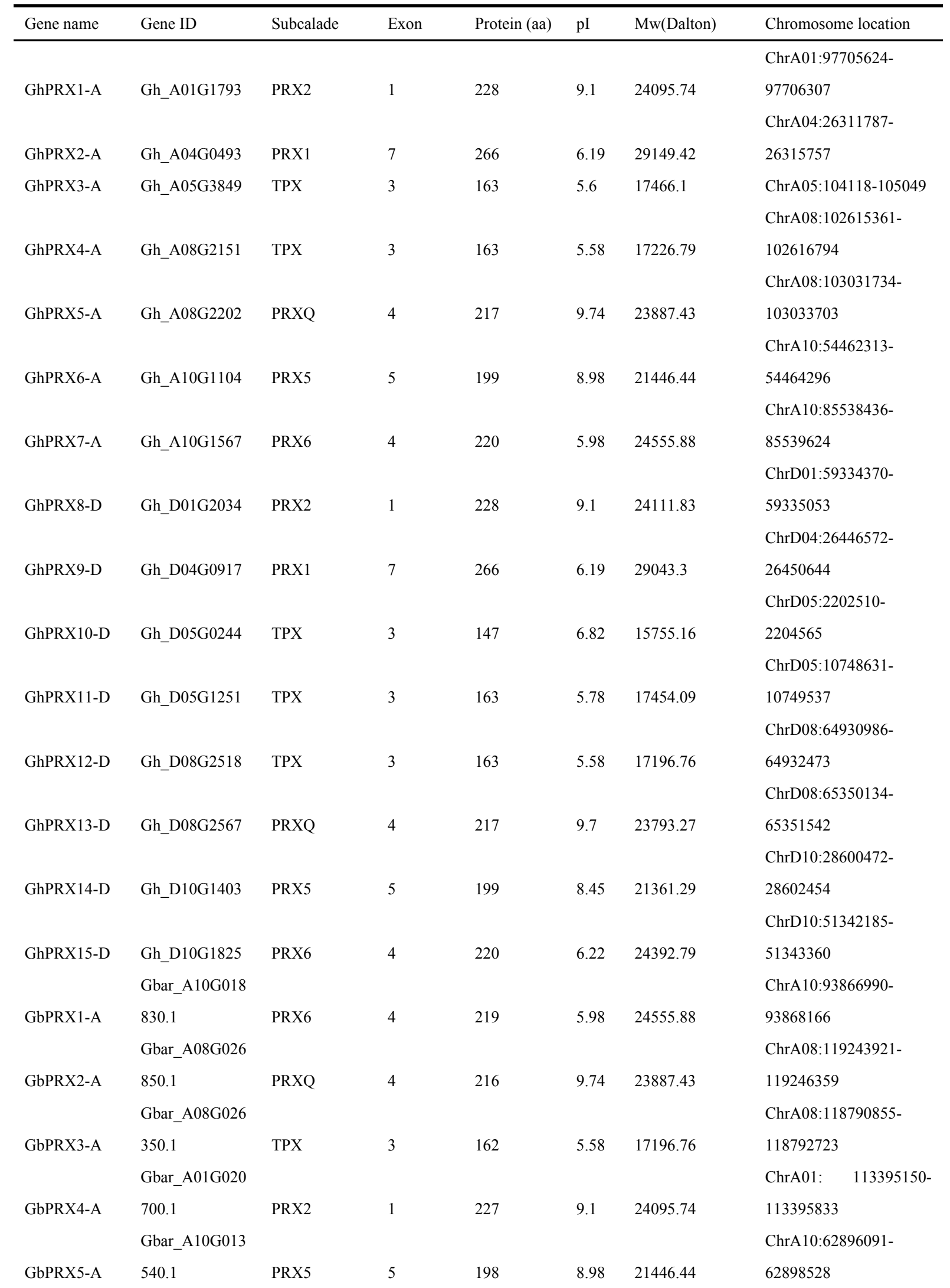




\begin{tabular}{|c|c|c|c|c|c|c|c|}
\hline & Gbar_A05G012 & & & & & & ChrA05:11767776- \\
\hline \multirow[t]{2}{*}{ GbPRX6-A } & 820.1 & TPX & 3 & 162 & 5.6 & 17466.1 & 11768707 \\
\hline & Gbar_D10G014 & & & & & & ChrD10:28146247- \\
\hline \multirow[t]{2}{*}{ GbPRX7-D } & 760.1 & PRX5 & 5 & 198 & 8.45 & 21333.23 & 28148956 \\
\hline & Gbar_D04G010 & & & & & & ChrD04:28395391- \\
\hline \multirow[t]{2}{*}{ GbPRX8-D } & 400.1 & PRX1 & 7 & 265 & 6.19 & 29103.4 & 28400177 \\
\hline & Gbar_D08G027 & & & & & & ChrD08:65405467- \\
\hline \multirow[t]{2}{*}{ GbPRX9-D } & 530.1 & PRXQ & 4 & 216 & 9.7 & 23793.27 & 65407385 \\
\hline & Gbar_D01G021 & & & & & & ChrD01:60905018- \\
\hline \multirow[t]{2}{*}{ GbPRX10-D } & 840.1 & PRX2 & 1 & 227 & 9.34 & 24091.84 & 60905701 \\
\hline & Gbar_D08G027 & & & & & & ChrD08:65009751- \\
\hline \multirow[t]{2}{*}{ GbPRX11-D } & 000.1 & TPX & 3 & 162 & 5.58 & 17196.76 & 65011737 \\
\hline & Gbar_D05G002 & & & & & & ChrD05:2189964- \\
\hline \multirow[t]{2}{*}{ GbPRX13-D } & 520.1 & TPX & 3 & 146 & 6.82 & 15755.16 & 2198116 \\
\hline & Gbar_D10G019 & & & & & & ChrD10:51564063- \\
\hline \multirow[t]{2}{*}{ GbPRX14-D } & 020.1 & PRX6 & 4 & 219 & 6.22 & 24392.79 & 51565371 \\
\hline & Gorai.009G135 & & & & & & Chr9:10193477- \\
\hline \multirow[t]{2}{*}{ GrPRX1 } & 600.1 & TPX & 3 & 162 & 5.78 & 17468.12 & 10194845 \\
\hline & Gorai.009G397 & & & & & & Chr9:56100514- \\
\hline \multirow[t]{2}{*}{ GrPRX2 } & 800.1 & PRX1 & 7 & 265 & 6.19 & 29043.3 & 56105218 \\
\hline & Gorai.009G026 & & & & & & \\
\hline \multirow[t]{2}{*}{ GrPRX3 } & 300.1 & TPX & 3 & 163 & 5.9 & 17491.13 & Chr9:2005154-2007919 \\
\hline & Gorai.011G158 & & & & & & Chr11:28114223- \\
\hline \multirow[t]{2}{*}{ GrPRX4 } & 200.1 & PRX5 & 10 & 198 & 7.71 & 21319.16 & 28116745 \\
\hline & Gorai.011G204 & & & & & & Chr11:49579270- \\
\hline \multirow[t]{2}{*}{ GrPRX5 } & 600.1 & PRX6 & 4 & 219 & 5.98 & 24498.87 & 49580743 \\
\hline & Gorai.002G243 & & & & & & Chr2:60733892- \\
\hline \multirow[t]{2}{*}{ GrPRX6 } & 200.1 & PRX2 & 1 & 227 & 9.24 & 24170.9 & 60734923 \\
\hline & Gorai.004G280 & & & & & & Chr4:61267661- \\
\hline \multirow[t]{2}{*}{ GrPRX7 } & 800.1 & TPX & 3 & 162 & 5.58 & 17196.76 & 61269611 \\
\hline & Gorai.004G285 & & & & & & Chr4:61634457- \\
\hline \multirow[t]{2}{*}{ GrPRX8 } & 400.1 & PRXQ & 4 & 216 & 9.7 & 23793.27 & 61636274 \\
\hline & & & & & & & Chr05:12175377- \\
\hline \multirow[t]{2}{*}{ GaPRX1 } & Ga05G1380 & TPX & 3 & 162 & 5.78 & 17500.12 & 12176307 \\
\hline & & & & & & & Chr10:80207013- \\
\hline GaPRX2 & Ga10G1482 & PRX5 & 5 & 198 & 8.98 & 21445.49 & 80208997 \\
\hline \multirow[t]{2}{*}{ GaPRX3 } & Ga05G0262 & TPX & 3 & 163 & 5.58 & 17538.2 & Chr05:2267143-2271319 \\
\hline & & & & & & & Chr04:36972413- \\
\hline \multirow[t]{2}{*}{ GaPRX4 } & Ga04G0982 & PRX1 & 7 & 265 & 6.19 & 29045.27 & 36976371 \\
\hline & & & & & & & Chr02:97187166- \\
\hline GaPRX5 & $\mathrm{Ga} 02 \mathrm{G} 1606$ & PRX2 & 1 & 227 & 9.1 & 24135.81 & 97187849 \\
\hline
\end{tabular}




\begin{tabular}{cccccccc} 
GaPRX6 & Ga08G2895 & PRXQ & 4 & 216 & 9.7 & 23846.33 & Chr08:128777936- \\
GaPRX7 & Ga08G2842 & TPX & 3 & 162 & 5.58 & 17196.76 & Chr08:128370617- \\
& & & & & & & \\
GaPRX8 & Ga10G0941 & PRX6 & 5 & 219 & 5.96 & 22794.86 & Chr10:20870875- \\
\hline
\end{tabular}

2 
Table 2 (on next page)

Alternative splicing profile analysis of $P R X$ genes. 
1 Table 2. Alternative splicing profile analysis of $P R X S$

\begin{tabular}{|c|c|c|c|c|c|c|}
\hline Transcript & $\begin{array}{l}\text { alternative } \\
\text { splicing } \\
\text { mode }\end{array}$ & alternative splicing site & $\begin{array}{l}\text { alternative } \\
\text { splicing } \\
\text { boundary }\end{array}$ & $\begin{array}{l}\text { Number } \\
\text { of clones }\end{array}$ & $\begin{array}{l}\text { ORF } \\
\text { length(bp) }\end{array}$ & $\begin{array}{l}\text { Amino } \\
\text { acid } \\
\text { length } \\
\text { (aa) }\end{array}$ \\
\hline GhPRX14-Leaf-AS1 & - & - & - & 24 & 597 & 199 \\
\hline GhPRX14-Leaf-AS2 & IR & The first intron 3' 15-bp base & AG/AA & 3 & 612 & 204 \\
\hline GhPRX14-Root-AS1 & - & - & - & 24 & 597 & 199 \\
\hline GhPRX14-Root-AS2 & IR & The first intron $3^{\prime} 15-b p$ base & AG/AA & 2 & 612 & 204 \\
\hline GhPRX14-Root-AS3 & $\begin{array}{l}\text { ES and } \\
\text { A3SS }\end{array}$ & $\begin{array}{l}\text { The fourth intron 3' 14-bp base, the } \\
\text { second, third, and fourth exons were } \\
\text { skipped. }\end{array}$ & $\begin{array}{l}\text { AG/AT, } \\
\text { GG/TT }\end{array}$ & 2 & 327 & 109 \\
\hline
\end{tabular}

2 